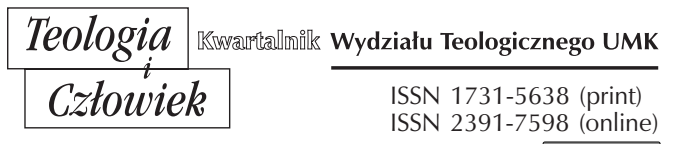

(ब) $(1)$

46(2019)2, ss. 19-56

KS. RYSZARD SELEJDAK

CONGREGAZIONE PER IL CLERO, CITTÀ DEL VATICANO

R.SELEJDAK@VIRGILIO.IT

ORCID:0000-0003-1225-7519

\title{
LO STATUTO PERSONALE E FUNZIONALE DEI DIACONI PERMANENTI NELL'INSEGNAMENTO DEL CONCILIO VATICANO II
}

DOI: http://dx.doi.org/10.12775/TiCz.2019.014

\begin{abstract}
The Personal Status and Role of Permanent Deacons in the Teaching of the Second Vatican Council. In their intention to restore the Permanent Diaconate, the Council Fathers decided to reinstate this ministry to its own proper and permanent hierarchical grade. The documents of the Second Vatican Council do not offer many indications that would give a comprehensive outline of the personal status and function of Permanent Deacons. With respect to their personal status, one thing is immediately apparent, namely: whoever is ordained to the diaconate forms part of the hierarchy, and is called to serve the mysteries of God and the Church. Upon these men, hands are imposed, not for the priesthood but for service. Deacons truly receive a Sacrament, the grace of which aids them to serve the People of God, in communion with the Bishop and his presbyterate, at the Altar, in preaching and in charity. The Council postulated that the diaconate could be conferred on married men of a mature age, and on suitable younger men for whom the observance of celibacy would be a prerequisite. They must remain detached from any vice, be pleasing to God and committed to good works in the sight of men. Regarding the role of Deacons, the Conciliar documents affirm that they are to preside over the liturgy of the Word, solemnly administer the Sacrament of Baptism, cherish and distribute the Eucharist, assist and bless marriages in the name of the Church, bring Viaticum to the dying, read the Scriptures to the faithful, instruct and exhort the People of God, preside at the Altar and at the Prayer of the Faithful, administer the Sacraments, preside at funerals and burials, and carry out works of charity and
\end{abstract}


support. The fact that the Conciliar documents limit themselves to speaking about the restoration of the diaconate, as a proper and permanent grade of the hierarchy, while leaving the final decision regarding its introduction into a given territory with the Bishops of that Region, albeit approved by the Holy Father, leaves one to think that the immediate reason for the restoration of the Permanent Diaconate was more practical and pastoral than it was doctrinal. The importance given to the restoration of the diaconate can also be evaluated at a symbolic level: with the restoration of a reality found in the Didascalia Apostolorum, together with the established diaconal nature of the Church as a servant of Her Lord and of humanity, in reclaiming a figure from the ancient Church, one is returning as it were to the beginning, that is to the original sources.

Key words: Council; Sacrament of Holy Orders; Permanent Diaconate; Personal Status and Fonction of Deacons.

\section{Streszczenie. Status personalny i funkcjonalny diakonów stałych w nauczaniu} Soboru Watykańskiego II. Ojcowie Soboru Watykańskiego II, uchwalając postulat przywrócenia posługi diakona stałego w Kościele łacińskim, wyrazili jedynie wolę ponownego przywrócenia tej posługi jako trwałego i właściwego stopnia hierarchicznego. Dokumenty soborowe nie podają wiele wskazówek, które w wyczerpujący sposób określałyby status personalny i funkcjonalny diakonów stałych. Jeśli chodzi o status personalny, jest faktem oczywistym, że diakoni są członkami hierarchii, chociaż na niższym stopniu, z zadaniem służenia tajemnicom Boga i Kościoła. W czasie święceń nakładane są na nich ręce nie dla kapłaństwa, lecz dla służby. Diakoni są umocnieni łaską sakramentalną, aby w diakonii liturgii, w przepowiadaniu i sprawowaniu dzieł miłosierdzia owocnie służyli ludowi Bożemu w jedności z biskupem i jego prezbiterium. Sobór, patrząc w przyszłość, ustalił, że święceń diakonatu można udzielać dojrzałym mężczyznom żyjącym w małżeństwie, a także odpowiednim młodszym mężczyznom, dla których jednak prawo celibatu musi pozostać niezmienne. Powinni oni odznaczać się odpowiednimi przymiotami ludzkimi i duchowymi, podobać się Bogu i nabywać niezbędne umiejętności, aby dobrze wypełniać swoją posługę. Odnośnie do statusu funkcjonalnego diakonów, dokumenty soborowe stwierdzają, że mogą oni przewodniczyć liturgii Słowa, uroczyście udzielać chrztu, przechowywać i rozdzielać Eucharystię, asystować i błogosławić w imieniu Kościoła związki małżeńskie, zanosić Wiatyk umierającym, przewodniczyć nabożeństwom i modlitwie wiernych, udzielać sakramentaliów, przewodniczyć obrzędom żałobnym i pogrzebowym oraz wykonywać dzieła miłosierdzia. Fakt, że Sobór wyraził jedynie wolę ponownego przywrócenia diakonatu, jako właściwego i stałego stopnia hierarchii, pozostawiając zgromadzeniom terytorialnym biskupów, za aprobatą Papieża, ostateczną decyzję o tym, czy ustanowić diakonat na ich terytoriach, sugeruje, że perspektywa przywrócenia stałego diakonatu była podyktowana bardziej względami praktyczno-duszpasterskimi aniżeli doktrynalnymi. Przywrócenie diakonatu należy również ocenić na poziomie symbolicznym. W czasie odnawiania oblicza i życia Kościoła w czasie Soboru Watykańskiego II zaistniała potrzeba podkreślenia wymiaru służebnego Kościoła. Doskonałym sposobem 
do uczynienia tego była wola przywrócenia diakonatu, obecnego już w starożytnym Kościele.

Słowa kluczowe: sobór; sakrament święceń; diakon stały; status personalny i funkcjonalny diakonów.

\section{INTRODUZIONE}

Il diaconato permanente è figura ministeriale certamente non nuova nella Chiesa, ma per quasi mille anni dimenticata. Si deve, infatti ricordare che la figura del diaconato, fin dal III secolo, inizia a svuotarsi di significato, pur non perdendo la caratteristica di ministero ordinato. Il diacono si trasforma in una figura liturgica, perdendo sempre più la connotazione di preposto alla carità ed alla condivisione. Nel Medioevo la Chiesa non sapeva che farsene del diaconato delle origini: doveva sbarazzarsene ${ }^{1}$. Il Concilio di Trento, riflettendo sull'Ordine come sacramento, ha riaperto la questione della sacramentalità del diaconato. Il Concilio Vaticano II ha prospettato il suo ripristino, riconsiderando il ministero ordinato nella sua articolazione: vescovi, presbiteri e diaconi. Il presente articolo cerca di presentare alcuni fattori che portarono il diaconato permanente allattenzione dei Padri del Concilio, lo sviluppo dei dibattiti conciliari riguardanti il ripristino del diaconato e soprattutto lo statuto personale e funzionale dei diaconi nei documenti conciliari.

\section{IL RINNOVATO INTERESSE VERSO IL DIACONATO}

Non cè dubbio che il vero sviluppo dell'idea di ripristino del diaconato permanente ebbe luogo solo dopo il $1945^{2}$. Si possono individuare

${ }^{1}$ Cf. G. Hammann, Storia del diaconato, Magnano-Biella 2004, p. 105.

2 Cf. R. Selejdak, Diakonat stały w świetle dokumentów Soboru Watykańskiego II, posoborowego Urzędu Nauczycielskiego Kościoła i narodowych «Rationes institutionis diaconorum permanentium», Warszawa 2010, pp. 68-71; G. Hornef, P. Winninger, Cronaca della restaurazione del diaconato (1945-1965), in: Il diaconato nella Chiesa e nel mondo di oggi, Padova 1968, pp. 320-346; P. J. Cordes, Dlaczego kapłan? Poszukiwanie odpowiedzi z Benedyktem XVI, Kielce 2009, pp. 206-208. 
quattro correnti di influenza che portarono il diaconato allattenzione dei dibattiti e quindi delle disposizioni del Concilio Ecumenico Vaticano II: lesperienza tedesca prima della seconda guerra mondiale, lesperienza di Dachau e gli sviluppi postbellici centrati in Germania, e in Francia, gli sviluppi pastorali legati alla missio ad gentes e alla catechesi e gli insegnamenti pontifici ${ }^{3}$.

Nel periodo prebellico, è da sottolineare l'opera di Josef Hornef, che studiò la documentazione sul ripristino di un diacono permanente ${ }^{4}$, e suggeriva un rinnovo del diaconato in una lettera del 1884 a un medico di Francoforte, J. K Passavant, che scriveva ad un amico che sarebbe diventato il futuro Cardinale Arcivescovo di Breslavia, Melchior van Diepenbrock. Passavant osservò che il sacerdozio era troppo separato dalla vita quotidiana delle persone e propose due possibili soluzioni:

La Chiesa può o permettere ai Sacerdoti di sposarsi nel modo in cui gli Uniati greci sono autorizzati a farlo, o può espandere la sfera di attività dei Diaconi, in modo che questi uomini, che potrebbero essere sposati, possano svolgere in parte l'ufficio di insegnamento e altre funzioni ecclesiastiche, mentre il prete (che dovrebbe quindi essere anziano) amministrerebbe esclusivamente i sacramenti, in particolare la confessione. I Vescovi, potrebbero scegliere i candidati Diaconi (arcidiaconi) dai ranghi più istruiti dei cosiddetti laici, in modo che la Chiesa potrebbe avere eccellenti ministri a sua disposizione ${ }^{5}$.

La lettera suggeriva la possibilità di un rinnovato diaconato come segno sacramentale di un ministero allargato. Non vi è alcuna indicazione che i suggerimenti di Passavant siano stati considerati oltre questo scambio di documenti. Il suddetto documento è segnale della particolare attenzione che si ebbe in Germania al diaconato e vide la crescita di tali idee nel contesto del movimento della Caritas. Tale movimento che fu

${ }^{3}$ Cf. W.T. Ditewig, The contemporary renewal of the diaconate, in: The Deacon Reader, a cura di J. Keating, Leominster 2006, pp. 27-29.

${ }^{4}$ Cf. J. Hornef, Il diaconato a vita, "Concilium" 4 (1968), pp. 142-154.

${ }^{5}$ Id., The genesis and growth of the proposal, in: Fundations for the renewal of the diaconate, a cura di National Conference of Catholic Bishops - Bishops' Committee on the Permanent Diaconate, Washington DC 1993, p. 6, traduzione propria. 
voluto dai vescovi tedeschi ${ }^{6}$ vide accrescere il loro operato a causa delle guerre mondiali. La rivista della Caritas pubblicò articoli che proposero e svilupparono la nozione di un diaconato rinnovato ${ }^{7}$.

Un altro fattore che fece maturare una nuova attenzione verso il diaconato fu durante le tragiche vicende della seconda guerra mondiale. Nel 1933, la Germania nazista aprì il suo primo campo di concentramento a Dachau. Un gran numero di religiosi e religiose vennero arrestati e, in accordo con le politiche naziste, non ricevettero alcun trattamento preferenziale nel campo. Incarcerati con la popolazione carceraria, continuarono a esercitare il loro ministero segretamente. Alla fine, i nazisti trasferirono il clero al Blocco numero 26, che divenne noto come der Priesterblock $^{8}$. Le discussioni avvenute durante l'incarcerazione, avevano riguardato le possibilità di rinnovo della Chiesa dopo la guerra. Una di queste possibilità era il ripristino del diaconato come stato permanente. Fr. Wilhelm Schamoni tenne nota di queste discussioni mentre era internato nel campo, e fu in grado di mettere al sicuro gli appunti dopo il crollo del Terzo Reich. Dopo la guerra, Schamoni e un altro ex prigioniero, P. Otto Pies, scrissero delle loro esperienze e riferirono delle discussioni circa un rinnovato Ordine diaconale 9 . Gravemente malato dopo la sua incarcerazione a Dachau, fu solo nel 1947 che Pies fu in grado di documentare le sue esperienze. Descrisse le discussioni sul futuro del ministero dopo la guerra, suggerendo che lo Spirito Santo stava chiamando all'esistenza nuovi ministeri, incluso il diaconato ${ }^{10}$. Wilhelm Schamoni, alla fine, rispondendo alle richieste di Pies e altri di esprimere le proprie riflessioni sulla questione, pubblicò un suo lavoro nel $1953^{11}$.

${ }^{6}$ Cf. M. Morche, Zur Erneuerung des ständigen Diakonats. Ein Beitrag zur Geschichte unter besonderer Berücksichtigung der Arbeit des Internationalen Diakonatszentrums in seiner Verbindung zum Deutschen Caritasverband, Freiburg 1996, pp. 15-21. (1934), p. 7.

7 Cf. G. von Mann, Der Caritasdiakonat und seine Erneurung, "Caritas" 7-8

${ }^{8}$ Cf. W.T. Ditewig, The contemporary renewal of the diaconate, art. cit., p. 31.

${ }^{9}$ Cf. ibidem, p. 32.

${ }^{10}$ Cf. O. Pies, Block 26: Erfahrungen aus dem Priesterleben in Dachau, "Stimmen der Zeit” 141 (1947-1948), pp. 10-28.

${ }^{11}$ Cf. W. Schamoni, Familienväter als geweihte Diakone, Paderborn 1953. 
Oltre allesperienza di questi sacerdoti e laici tedeschi, reduci dai drammatici anni vissuti in carcere, che cominciarono ad ipotizzare un nuovo ministero ecclesiale, diverso dal presbiterato, vi furono altri che maturarono questa sensibilità partendo dalla missio ad gentes, ovvero dallesperienza di servizio ai poveri e alle persone più disagiate dalla società. A questa causa si dedicò in particolare Hannes Kramer ${ }^{12}$ che avvertì questa esigenza e prese a formarsi per un eventuale percorso diaconale. Egli si iscrisse ai corsi di un seminario destinato alla preparazione degli operatori della Caritas in Friburgo, che prestavano particolare attenzione allaiuto ai bisognosi di ogni specie. A partire dal 1957, Kramer, fondò la prima "Comunità del Diaconato" (Diakonatskreis), a Friburgo, con altri sei operatori sociali, come lui ispirati e motivati dall'eventualità di un diaconato al servizio dei poveri. Questo organismo aveva il compito sia di studiare e promuovere la reintroduzione del diaconato in modo stabile nella Chiesa, e sia di formare coloro che si mostravano interessati a questo ministero ${ }^{13}$.

Un'altra "Comunità del Diaconato" venne creata a Monaco nel $1954^{14}$, con il fattivo appoggio dell'Arcivescovo J. Döpfner ${ }^{15}$ e del teologo K. Rahner. In quel periodo fiorirono una serie di studi su tale argomento,

12 Cf. O. Plater, Many Servants: An Introduction to Deacons, London 2004, pp. 63-64.

13 Cf. E. Petrolino, Il Concilio Vaticano II e il diaconato. La Chiesa mistero di comunione e sevizio, Città del Vaticano 2013, p. 23; id., Diaconato. Servizio-missione dal Concilio Vaticano II a Giovanni Paolo II, Città del Vaticano 2006, pp. 21-22; M. Marczewski, Diakonat, in: Encyklopedia Katolicka, vol. III, a cura di R. Łukaszyk, L. Bieńkowski, F. Gryglewicz, Lublin 1979, col. 1245; id., Odnowa diakonatu stałego w Kościele łacinskim, "Novum" 4-5 (1979), p. 149; M. Morche, Zur Erneuerung des Ständigen Diakonats. Ein Beitrag zur Geschichte unter besonderer Berücksichtigung der Arbeit des Internationalen Diakonatszentrums in seiner Verbindung zum Deutschen Caritasverband, pp. 15-18; H. Kramer, M. Morche, Caritas und Diakonatsbewegung in der ersten Phase (1905-1992), "Diaconia Christi" 29 (1994) 3-4, pp. 23-24; S. Sander, Das Amt des Diakons. Eine Handreichung, Freiburg im Breisgau 2008, p. 90.

${ }^{14}$ Cf. K. Baumann, Ständinger diakonat. Eine frucht des II. Vatikanus, "Roczniki Pastoralno-Katechetyczne” 60 (2013), pp. 11-13.

${ }^{15}$ Cf. G. Martina, Storia della Chiesa, vol. IV, Brescia 1995, pp. 296-300; 331-334. 
specie quelli dello storico protestante $\mathrm{H}$. $\mathrm{Krimm}^{16}$, e quelli derivati dalla testimonianza di alcuni diaconi luterani ${ }^{17}$.

Durante il decimo Congresso di Pastorale Liturgica tenutosi ad Assisi nel settembre 1956 Mons. O. Van Bekkum, vicario apostolico di Ruteng in Indonesia, auspicò e sostenne fortemente il ripristino del diaconato $^{18}$. Soprattutto nelle terre di missione vu fu una buona accoglienza di tale istanza ${ }^{19}$.

Oltre alle istanze provenienti dalle esperienze tedesche, un importante sviluppo nel contemporaneo rinnovamento del diaconato si ebbero con alcune disposizioni di Pio XII. Il 30 novembre 1947, con Costituzione Apostolica Sacramentum Ordinis ${ }^{20}$, il Pontefice stabilì chiaramente la materia e la forma del Sacramento dell'Ordine ${ }^{21}$. Tra le altre preoccupazioni, la domanda persisteva sul come dovevano essere considerati gli Ordini minori e maggiori rispetto al presbiterato. Papa Pacelli risolse la questione dichiarando che per le ordinazioni al diaconato, al presbiterato e allepiscopato, la materia e la forma sono date dall'imposizione delle mani e la preghiera consacratoria ${ }^{22}$. Inoltre il Pontefice, fissò le parti della preghiera consacratoria che sono necessarie ad validitatem:

Emitte in eum, quaesumus, Domine, Spiritum Sanctum, quo in opus ministerii tui fideliter exsequendi septiformis gratiae tuae munere roboretur $^{23}$.

${ }^{16}$ Cf. C. Bridel, Aux seuils de l'espérance: le diaconat en notre temps, Neuchâtel-Paris 1071, pp. 39-41.

17 Cf. E. Petrolino, Il Concilio Vaticano II e il diaconato, p. 24.

18 Cf. W. T. Ditewig, The Emerging Diaconate: Servant Leaders in a Servant Church, New York 2007, pp. 106-107.

19 Cf. P. Hofinger, Pastorale liturgica nella cristianità missionaria, Bruxelles 1957, pp. 105-116; M. D. Epagneul, Du rôle du diacre dans l'Eglise d'aujourd'hui, "Nouvelle Revue Théologique" 79 (1957), pp. 153-168; J. E. Monast, On les croyait chrétiens, Paris 1969, pp. 120-124.

20 Cf. Pius PP. XII, Constitutio Apostolica de Sacris Ordinibus Diaconatus, Presbyteratus et Episcopatus: Sacramentum Ordinis, 30.11.1947, n. 4, AAS 40 (1948), p. 7.

${ }^{21}$ Cf. C. Giraudo, Il Presbitero nella preghiera di ordinazione, in: Il Presbitero nella Chiesa dopo il Vaticano II, a cura di P. Sorci, Trapani 2005, pp. 65-67.

${ }^{22}$ Cf. Pius PP. XII, Constitutio Apostolica Sacramentum Ordinis, n. 4, p. 66.

${ }^{23}$ Ibidem, n. 5, p. 6. 
Di particolare interesse fu il discorso di Pio XII nel secondo Congresso per l'Apostolato dei laici, svoltosi a Roma nell'ottobre 1957:

Nous savons qu'on pense actuellement à introduire un ordre du diaconat conçu comme fonction ecclésiastique indépendante du sacerdoce. L'idée, aujourd'hui du moins, n'est pas encore mûre. Si elle le devenait un jour, rien ne changerait à ce que Nous venons de dire sinon que ce diaconat prendrait place avec le sacerdoce dans les distinctions que Nous avons indiquées ${ }^{24}$.

Papa Pacelli riconobbe la possibilità del ripristino del diaconato "come funzione ecclesiale indipendente dal sacerdozio, che avrebbe fatto scaturire i suoi titolari dallo stato laico". Il Pontefice aggiungeva, tuttavia, che un tale cambiamento non gli sembrava possibile nell'immediato, poiché i tempi non erano ancora sufficientemente maturi per accogliere questa novità. Tale espressione del Pontefice fece sorgere nuovi sostenitori del diaconato e nuovi entusiasmi ${ }^{25}$.

Con l'indizione del Concilio, le attese coltivate fino a quel momento trovarono un luogo per poter essere realizzate.

\section{LA PREPARAZIONE AL CONCILIO}

Domenica 25 gennaio del 1959, Papa Giovanni XXIII convocò dopo la Santa Messa, i cardinali presenti a Roma nella festa della Conversione di San Paolo:

Venerabili Fratelli e Diletti Figli Nostri! Pronunciamo innanzi a voi, certo tremando un poco di commozione, ma insieme con umile risolutezza di proposito, il nome e la proposta della duplice celebrazione: di un Sinodo Diocesano per l'Urbe, e di un Concilio Ecumenico per la Chiesa universale ${ }^{26}$.

24 Pius PP. XII, Discours aux participants au IIe Congrés mondial dellapostolat des laics, Samedi 5 octobre 1957, AAS 49 (1957), p. 925.

${ }^{25}$ Cf. C. Falconi, La Chiesa e le organizzazioni cattoliche in Europa, Ivrea 1960, pp. 114-116.

${ }^{26}$ Ioannes PP. XXIII, Sollemnis allocutio, 25.01.1959, AAS 51 (1959), pp. 65-69. 
Questo annuncio creò grande fermento nella Chiesa, ed anche il discorso sul diaconato trovò un nuovo ed ecclesiale luogo di discussione.

A partire dal 17 maggio 1959 si costituì una commissione "antepraeparatoria” presieduta dal Card. D. Tardini, con Mons. P. Felici come segretario $^{27}$. Una delle prime discussioni di questo gruppo fu quella di consultare i vescovi, i superiori religiosi e le Università cattoliche sui temi da sottoporre al Concilio ${ }^{28}$. Successivamente, Giovanni XXIII costituì dieci commissioni, parallele alle Congregazioni romane e in rapporto con esse, chiamate a redigere, sulla base dei risultati delle consultazioni effettuate, dei progetti di testi da proporre per la discussione ${ }^{29}$. Tale consultazione portò a 2150 suggerimenti, contenuti in circa 1500 risposte di cui parecchie collettive. Ne risultano 341 reazioni favorevoli al diaconato permanente; 222 incoraggiavano, inoltre, l'ordinazione di uomini coniugati, mentre 12 risultavano contrari ${ }^{30}$.

Tra le varie risposte favorevoli emersero anche delle precisazioni: molti ritenevano il diaconato come una risposta alla crescente penuria di preti; dall'Europa si sottolineava il ruolo caritativo e sociale; dai Paesi in via di sviluppo si valorizzava il ministero legato alla Parola di Dio con la catechesi e la predicazione. Altre risposte rilevavano vedute molto diverse: alcuni vescovi manifestarono entusiasmo, soprattutto in America Latina, altri espressero il timore di una apertura al matrimonio per i preti. Tre vescovi degli Stati Uniti incoraggiarono la creazione di ministri che non siano costretti all'uso del latino ed insistettero sulla necessità di una buona formazione teologica che li radichi correttamente nel ministero. Parecchi vescovi asiatici e i nunzi di Belgio, Francia e Gran Bretagna suggerirono che il diaconato potrebbe essere opportunamente conferito a pastori protestanti convertiti al Cattolicesimo ${ }^{31}$.

In questa fase si raccolsero pareri sulle funzioni che i diaconi avrebbero dovuto svolgere: la distribuzione della Comunione e la catechesi raccolsero molti consensi così anche la reposizione del Santissimo Sacra-

${ }^{27}$ Cf. O. H. Pesch, Das zweite Vatikanische Konzil, Würzburg 1993, p. 56.

${ }^{28}$ Cf. G. Martina, Storia della Chiesa, vol. III, Brescia 1995, pp. 275-305.

${ }^{29}$ Cf. O. H. Pesch, Das zweite Vatikanische Konzil, p. 59.

${ }^{30}$ Cf. E. Petrolino, Il Concilio Vaticano II e il diaconato, p. 25.

${ }^{31}$ Cf. G. Palazzini, Il Concilio Ecumenico Vaticano II: tra cronaca e storia, Roma 1966, pp. 169-170. 
mento e l'assistenza ai moribondi e la predicazione, l'assistenza al matrimonio e l'amministrazione dei beni. Fra le altre responsabilità segnalate, vengono indicate anche l'animazione delle opere sociali, la conservazione degli archivi, il viatico e la presidenza delle esequie ${ }^{32}$.

Una posizione favorevole al diaconato venne diffusa anche dalla "Comunità del Diaconato": si tratta di un testo firmato da 90 personalità di spicco, tra cui i teologi Y. Congar e K. Rahner, che lamentava il sovraccarico dei preti, specie in territorio di missione, e l'urgenza di fornire loro degli ausiliari in grado di aiutarli innanzitutto nell'ambito liturgico, e poi anche nei servizi della Parola e della carità. Secondo tale prospettiva, i futuri diaconi, dovevano operare nelle parrocchie, occupando il rango "inferiore" nei gradi del Sacramento dell'Ordine e costituendo il legame tra clero e popolo cristiano, e consentendo alla funzione propria del sacerdote di apparire con maggiore rilievo. L'unità del servizio diaconale e la comunione con gli altri gradi dell'Ordine dovevano servire a garantire dal riferimento costante all'Eucaristia ${ }^{33}$.

Tre delle dieci commissioni preparatorie ricevettero mandato di esaminare la questione del diaconato. La prima, incaricata della "disciplina dei sacramenti", elaborò un progetto di schema, completato nel 1961, il cui capitolo iniziale si intitolava "dell'istituzione del diaconato permanente o stabile"34. Il testo sosteneva una rivalutazione degli ordini minori e del diaconato, soprattutto laddove la carenza di preti era già consistente. Essi, in tale disegno, potevano essere sposati ma non abilitati a risposarsi, e sarebbero stati ministri del vescovo e della Chiesa e avrebbero assunto funzioni "sacre" (servizio dell'altare, sacramenti, ministero della Parola), compiti "ministeriali o pastorali" (catechesi, carità, animazione, ecc.) e funzioni "giurisdizionali" (tribunali) ed amministrative. La Commissione incaricata dell'attività missionaria redasse uno schema sulla "disciplina del clero", prevedendo una restaurazione del diaconato come aiuto per i preti che risultavano spesso impossibilitati a svolgere la loro opera evangelizzatrice presso i non cristiani e scartando lobiezione secondo la quale un

${ }^{32}$ Cf. E. Petrolino, Il Concilio Vaticano II e il diaconato, p. 25.

${ }^{33}$ Cf. M. Morche, Zur Erneuerung des ständigen Diakonats, op. cit, pp. 34-37.

${ }^{34}$ Cf. H. de Lubac, Carnets du Concile, vol. I, Paris 2007, pp. 124-125. 
diaconato coniugato avrebbe potuto nuocere al reclutamento sacerdotale ${ }^{35}$. La Commissione per le Chiese orientali incoraggiava la restaurazione del diaconato laddove essa fosse caduto in disuso ${ }^{36}$. La Commissione centrale, il 17 gennaio 1962, esaminò il progetto della Commissione per la disciplina dei sacramenti e si espresse con 2 approvazioni incondizionate, 25 pareri contrari e 29 pareri iuxta modum. Il dibattito registrò gli interventi contrari dei Cardinali: E. Rufini (Palermo), G. Siri (Genova) e J. Frings (Colonia), mentre P. Richaud (Bordeaux), J. Döpfner (Monaco) e B. Alfriuk (Utrecht) si pronunciarono a favore ${ }^{37}$. Non mancò chi dichiarò la sua opposizione al ripristino del diaconato ponendosi a difesa di una maggiore valorizzazione dei catechisti e dei laici impegnati, per sventare il rischio che si giungesse alla costituzione di una sorta di "doppio clero" 38 .

Si espressero a favore della restaurazione del diaconato il Card. A. Larrona, Prefetto della Congregazione dei Riti, e il Patriarca melchita Maximos IV. Mons. M. Lefebvre (Dakar) approvò anch'egli l'eventualità di un diaconato, ma escluse la possibilità dei diaconi coniugati che, sarebbero stati male accolti in territorio di missione e avrebbero rischiato di porre problemi di ordine psicologico ai preti. Anche il Card. G. Agagianian presidente della Commissione delle Missioni, il cui schema fu dibattuto il 28 e 29 marzo 1962, rilevando che 100 prelati missionari incoraggiano la restaurazione, propose il ripristino del diaconato come rimedio alla mancanza dei preti. Egli sostenne inoltre che il celibato, pur restando lopzione preferibile, avrebbe potuto scoraggiare o demotivare gli eventuali candidati. Le reazioni dei membri della Commissione centrale continuarono tra spinte entusiastiche e battute d'arresto ${ }^{39}$.

35 Cf. A. von Teuffenbach, La commissione teologica preparatoria del Concilio Vaticano II, "Annuario de Historia de la Iglesia” 21 (2012), pp. 231-233.

${ }^{36}$ Cf. S. Noceti, La costituzione gerarchica della Chiesa e in particolare l'episcopato, in: Commentario ai documenti del Vaticano II, a cura di S. Nocetti, R. Repole, Roma 2006, p. 307.

37 Cf. A. von Teuffenbach, La commissione teologica preparatoria del Concilio Vaticano II, art. cit., pp. 240-243.

${ }^{38}$ Cf. E. Petrolino, Il Concilio Vaticano II e il diaconato, p. 28.

${ }^{39}$ Cf. ibidem. 


\section{I LAVORI CONCILIARI}

La seduta di apertura del Concilio Vaticano II, l'11 ottobre 1962, vide una solenne Liturgia con i 2540 membri con diritto di voto, in abiti episcopali nella basilica di San Pietro.

Il primo documento ad essere discusso nel Concilio fu un prima schema sulla Chiesa e occupò i Padri dal primo al 7 dicembre. Questo testo, poi ricusato dall'assemblea, non conteneva alcun riferimento al diaconato.

Il testo De Ecclesia predisposto dalla Commissione dottrinale preparatoria, infatti, non aveva nessun riferimento ai diaconi. Il tema apparve nel textus prior al n. 15. Dopo le affermazioni sulla natura del presbiterato, si invitava a valutare l'ipotesi di una restaurazione del diaconato permanente e se ne delineavano le funzioni. La Commissione di coordinamento, insediatasi a partire dal 6 gennaio 1963, dopo aver valutato i 21 schemi approntati, affidò alla Commissione teologica il compito di riscrivere il testo sulla Chiesa, tema sul quale i vescovi di Germania ed Austria fecero elaborare, da parte loro, un nuovo Progetto. Nello schema della Commissione teologica al secondo capitolo, dedicato alla struttura gerarchica della Chiesa, nell'articolo 15 fu inserito un riferimento a preti e diaconi ${ }^{40}$. Venne ripreso per questo lo Schema tedesco, anche se con due significative differenze: non veniva dichiarata espressamente la sacramentalità dell'ordinazione e si insisteva sulla collaborazione con i presbiteri e non solo con i vescovi ${ }^{41}$. Il dibattito che ne seguì fu molto acceso. Per alcuni Padri non era maturo il tempo per una riflessione sul tema ${ }^{42}$, altri espressero la loro contrarietà verso il ripristino di una figura ministeriale di cui non videro necessità o utilità ${ }^{43}$, altri si mostrarono favorevoli, soprattutto mossi da necessità ecclesiali pratiche ${ }^{44}$, altri ancora, seppur

40 Cf. ibidem, s. 29.

${ }^{41}$ Cf. S. Noceti, La costituzione gerarchica della Chiesa e in particolare l'episcopato, art. cit., p. 308.

${ }^{42}$ Cf. Jubany Arnau (Acta Synodalia, II, II, pp. 580-586).

${ }^{43}$ Si veda: Franić, a nome di 16 vescovi della Jugoslavia (cf. Acta Synodalia, II, II, pp. 378-384); Spellman (cf. ibidem, pp. 82-84); McIntyre (cf. ibidem, p. 652); McCann (cf. ibidem, pp. 810-812).

${ }^{44}$ Cf. Gay (Acta Synodalia, II, II, pp. 593-595). 
favorevoli al ripristino, chiedevano garanzie per il mantenimento di una condizione celibataria ${ }^{45}$.

Durante la sessione del 7 e l'8 ottobre 1963 il Card. Döpfner ${ }^{46}$, Mons. J. Landazuri Rickets ${ }^{47}$ a nome di 95 vescovi dell'America Latina, e il Card. L.J. Suenens ${ }^{48}$ presentarono le ragioni bibliche, teologiche e storiche per il ripristino di un ministero diaconale, le cui funzioni erano ritenute necessarie alla vita della Chiesa e illustrarono le positive implicazioni per la prassi ecclesiale nelle diocesi e nelle parrocchie. Questi tre interventi, di forte spessore teologico, orientarono l'assemblea verso l'approvazione della proposta.

Nella seduta del 10 ottobre del 1963, parecchi prelati attivi in territori di missione appoggiano la proposta di restaurazione, ed il portavoce dell'episcopato boliviano, Mons. J. Maurer, sottolineò come il diacono avrebbe potuto richiamare e additare ai credenti la necessaria umiltà di ogni servizio cristiano e, cosa più importante, della Chiesa stessa ${ }^{49}$.

In particolare secondo il modo di vedere dei vescovi tedeschi, il diaconato avrebbe completato certamente la gerarchia, ma doveva essere conferito a uomini che già esercitano funzioni diaconali, con l'intento di aiutare i sacerdoti nella carità verso poveri, ma anche nella pastorale. Permanevano delle riserve nei riguardi del diaconato degli sposati. E così, sullo sfondo del rimedio alla penuria di sacerdoti e del dibattito sul diaconato degli sposati, eventuale preludio di un sacerdozio uxorato ${ }^{50}$, si delinearono due ragioni per il ripristino del diaconato come grado permanente: i bisogni della cura animarum, cioè del farsi carico dei battezzati, e delle richieste di evangelizzazione dei non battezzati, mediante lo svolgimento dei compiti necessari alla vita della $\mathrm{Chiesa}^{51}$; una ragione

45 Si veda: Bacci (cf. Acta Synodalia, II, II, p. 87); Calewaert (cf. ibidem, p. 692); Cordero (cf. ibidem, p. 711); Carraro (cf. ibidem, pp. 524-525).

${ }^{46}$ Cf. Acta Synodalia, II, II, pp. 227-230.

${ }^{47}$ Cf. ibidem, pp. 314-317.

${ }^{48}$ Cf. ibidem, pp. 312-320.

49 Cf. ibidem, pp. 340-341.

${ }^{50}$ Cf. A. Borras, Le diaconat au risque de sa nouveauté?, Bruxelles 2007, p. 24;

D. Gonneaud, La sacramentalié du ministère diaconal, "Revue Théologique de Louvain" 36 (2005), p. 5.

${ }^{51}$ Cf. K. Rahner, Lenseignement de Vatican II sur le diaconat et sa restauration, 
dottrinale, visto che il diaconato, grado proprio e permanente, fa parte della gerarchia e rientra nel ministero ecclesiale di divina istituzione. "Completare la gerarchia" significa in definitiva valorizzare la diversità interna del ministero ordinato; indirettamente, ciò significa anche che esso non si riduce al sacerdozio dei vescovi e dei preti ${ }^{52}$.

Nella votazione del 30 ottobre 1963, si affrontò il quesito sul ripristino del diaconato permanente con un risultato del $75 \%$ di voti favorevoli ${ }^{53}$, a fronte di un elevato $25 \%$ di voti contrari. La Sottocommissione V, che lavorò nell'intersessione, esaminò a lungo le obiezioni e gli argomenti emersi nel dibattito, tra cui la possibilità di ordinare uomini sposati, la sacramentalità del diaconato e l'appartenenza alla gerarchia in grado inferiore, le specifiche funzioni, il pericolo di clericalizzazione dei laici ${ }^{54}$. Nella votazione del 28 settembre 1964, ci furono solo 142 non placet ${ }^{55}$.

Per evitare difficoltà ulteriori nel dibattito conciliare, il Card. Suenens, Co-Presidente del Concilio, propone allora un voto indicativo su vari temi aspramente dibattuti. Pertanto il 29 ottobre 1964, lo scrutinio sul diaconato uxorato raccolse 1588 voti favorevoli su un totale di 2120 votanti. Venne costituita una sottocommissione con il compito di redigere un nuovo testo sui sacerdoti e i diaconi. Questo gruppo propose di porre i due temi alla fine del terzo capitolo della Costituzione sulla Chiesa, ovvero di rendere il diaconato accessibile a giovani uomini celibi e di demandare la decisione riguardante il matrimonio al giudizio del Papa. La Commissione dottrinale studiò questo testo tra il 6 e l'11 marzo 1964, mentre la Commissione di coordinamento lo approvò nel mese di giugno seguente. La versione definitiva venne inviata ai Padri il 3 luglio $1964^{56}$. Alla presentazione del progetto in assemblea plenaria, il relatore mise in risalto la prudenza del testo rispetto al carattere sacramentale del diaco-

in: Le diacre dans l'Église et le monde d'aujourd'hui, a cura di P. Winninger, Y. Congar, Paris 1966, p. 227.

${ }^{52}$ Cf. L. Collombert, La rétablissement du diaconat permanent. Regards sur l'histoire, “Cahiers de l’Atelier” 491 (2001), p. 34.

${ }^{53}$ Cf. E. Petrolino, Il Concilio Vaticano II e il diaconato, p. 29.

${ }^{54}$ Cf. S. Noceti, La costituzione gerarchica della Chiesa e in particolare l'episcopato, art. cit., p. 308.

${ }^{55}$ Cf. ibidem.

${ }^{56}$ Cf. A. Borras, Le diaconat au risque de sa nouveauté?, p. 30. 
nato, soprattutto nel passaggio che sottolineava il legame privilegiato del ministero con il servizio del vescovo, e sottolineò inoltre l'inopportunità di reintrodurlo quale risoluzione proposta alla mancanza di preti. Al momento del dibattito, furono proposte ed accettate due modifiche: la prima chiedeva il consenso del Papa per lordinazione di diaconi sposati, mentre la seconda richiamava la possibilità di ordinare "giovani" vincolati al celibato ${ }^{57}$.

Nella votazione sul numero 29 della Costituzione sulla Chiesa $\mathrm{Lu}$ men gentium dedicato al diaconato avvenuta il 21 settembre del 1964, la parte sullo statuto funzionale diaconale raccolse 2055 voti su un totale di 2152 votanti; l'ammissione di diaconi coniugati "di età matura" fu accettata da 1598 Padri su 2229 e l'eventualità di accettare "giovani” senza obbligo al celibato fu rigettata da 1364 voti su 2211 votanti. Due mesi dopo, la suddetta Costituzione fu approvata e promulgata ${ }^{58}$.

La promulgazione, un anno più tardi, del Decreto sullattività missionaria della Chiesa Ad gentes metterà in luce accenti diversi sui compiti assegnati ai futuri diaconi permanenti. Si passa da un accento della Costituzione Lumen gentium (n. 29) su compiti principalmente liturgici - in seguito ai quali vengono i compiti di carità e di assistenza - a un accento del Decreto Ad gentes (n. 16) su compiti legati al ministero della Parola come catechisti, alla direzione in nome del vescovo o del parroco delle comunità remote e lontane e alla carità nelle opere sociali o caritative. Queste diversità d'accento rivelano le tensioni presenti fin dall'inizio nella "riattivazione" del diaconato permanente. L'impressione che si ricava è quella di un diaconato riferito a compiti fino ad allora assunti dai sacerdoti o dai catechisti. I diaconi apparivano come degli ausiliari nella pastorale ${ }^{59}$. Risulta essere interessante notare come la Costituzione pastorale sulla Chiesa nel mondo contemporaneo Gaudium et spes, non faccia alcuna menzione né dei diaconi né del diaconato. Molti autori ritengono che "questo ministero è compreso anzitutto, se non esclusivamente, come un compito intra-ecclesiale"60. Per lo storico Daniel Moulinet, il testo pro-

${ }^{57}$ Cf. D. Vitali, Per una teologia del diaconato: la lezione conciliare, "Rassegna di Teologia” 55 (2014), pp. 111-132.

${ }^{58}$ Cf. E. Petrolino, Il Concilio Vaticano II e il diaconato, p. 30.

${ }_{59}$ Cf. O. H. Pesch, Il Concilio Vaticano secondo, p. 278.

${ }^{60}$ Cf. P. Weber, Vatican II et le diaconat permanent, in: Diaconat XXI siècle. Actes 
mulgato della Costituzione sulla Chiesa Lumen gentium (n. 29) testimonia le esitazioni e le incertezze delle prospettive dei Padri conciliari; da una parte, il diaconato poteva apparire agli occhi di alcuni come il preludio allaccesso di uomini sposati al sacerdozio; la questione del suo ripristino incitava altri alla rivitalizzazione del celibato sacerdotale. Rimane il fatto che i Padri Conciliari vedevano il ministero diaconale come un aiuto ai sacerdoti e un servizio della carità ${ }^{61}$.

\section{IL DIACONATO NEI TESTI CONCILIARI}

I dibatti conciliari portarono di fatti alla stesura di documenti che rimangono il modo attraverso i quali la Chiesa è chiamata a camminare per essere segno e strumento di Cristo per la salvezza degli uomini.

\subsection{LA COSTUZIONE DOGMATICA SULLA DIVINA RIVELAZIONE DEI VERBUM}

La Costituzione dogmatica sulla Divina Rivelazione Dei Verbum promulgata il 18 novembre 1965, al numero 25, fa riferimento ai diaconi:

Quapropter clericos omnes, imprimis Christi Sacerdotes ceterosque qui ut diaconi vel catechistae ministerio verbi legitime instant, assidua lectione sacra atque exquisito studio in Scripturis haerere necesse est, ne quis eorum fiat «verbi Dei inanis forinsecus praedicator, qui non est intus auditor», dum verbi divini amplissimas divitias, speciatim in sacra Liturgia, cum fidelibus sibi commissis comunicare debet. Pariter Sancta Synodus christifideles omnes, praesertim sodales religiosos, vehementer peculiariterque exhortatur, ut frequenti divinarum Scripturarum lectione «eminentem scientiam Iesu Christi» (Phil. 3, 8) ediscant. «Ignoratio enim Scripturarum ignoratio Christi est». Libenter igitur ad sacrum textum ipsum accedant, sive per sacram Liturgiam divinis eloquiis confertam, sive per piam lectionem, sive per institutiones ad id aptas aliaque subsidia, quae approbantibus et curantibus Pastoribus Ecclesiae ubique

du colloque de Louvain-la Neuve (13-15 settembre 1991), a cura di A. Haquin, P.Weber, Bruxelles-Ottawa-Paris-Genève 1997, p. 90.

${ }^{61}$ Cf. D. Moulinet, La restauration conciliaire (1959-1964), in: Le diaconat permanent. Relectures et perspectives, ed. D. Moulinet, B. Dumons, Paris 2007, p. 65. 
nostro tempore laudabiliter diffunduntur. Meminerint autem orationem concomitari debere Sacrae Scripturae lectionem, ut fiat colloquium inter Deum et hominem; nam «illum alloquimur, cum oramus; illum audimus, cum divina legimus oracula» ${ }^{62}$.

Il dettato conciliare, nel raccomandare a tutto il Popolo di Dio ${ }^{63}$, ma soprattutto ai chierici, principalmente ai sacerdoti, parla poi dei "quanti, come i diaconi o i catechisti, attendono legittimamente al ministero della parola" affinché "conservino un contatto continuo con le Scritture mediante una lettura spirituale assidua e uno studio accurato" per farne meglio parte ai fedeli ${ }^{64}$.

\subsection{LA COSTITUZIONE SULLA SACRA LITURGIA SACROSANCTUM CONCILIUM}

La Costituzione sulla sacra liturgia Sacrosanctum Concilium approvata il 4 dicembre 1963, non parla di un diaconato "permanente". Essa promuove la celebrazione della Parola di Dio alla vigilia delle feste più solenni, in alcune ferie dell'Avvento e della Quaresima, nelle domeniche e nelle feste, soprattutto in mancanza di un sacerdote:

Foveatur sacra Verbi Dei celebratio in solemniorum festorum pervigiliis, in aliquibus feriis Adventus et Quadragesimae, atque in dominicis et diebus festis, maxime in locis quae sacerdote carent: quo in casu celebrationem diaconus vel alius ab Episcopo delegatus dirigat ${ }^{65}$.

Tale trattazione contestualizzata nel numero $35 \$ 4$ ha la finalità di sottolineare l'unità di ritus e verbum ${ }^{66}$. L'insegnamento conciliare riferisce

62 Sacrosanctum Concilium Oecumenicum Vaticanum II, Constitutio dogmatica de Divina Revelatione Dei Verbum, 18.11.1965, n. 25, AAS 58 (1966), p. 829.

${ }^{63}$ Cf. B. Maggioni, "Impara a conoscere il volto di Dio nelle parole di Dio". Commento alla «Dei Verbum», Padova 2001, pp. 131-134.

${ }^{64}$ Cf. I de la Potterie, La lettura della Sacra Scrittura "nello Spirito", "Communio" 14 (1986), pp. 37-38.

65 Sacrosanctum Concilium Oecumenicum Vaticanum II, Constitutio de sacra Liturgia Sacrosanctum Concilium, 4.12.1963, n. 35, AAS 56 (1964), p. 109.

${ }^{66}$ Cf. L. Girardi, Commento, in: Commentario ai documenti del Vaticano II. Sacrosanctum concilium. Inter mirifica, a cura di S. Noceti, R. Repole, Bologna 2014, pp. 153-154. 
del rapporto tra liturgia e Sacra Scrittura. Per cui quando si celebra, tanto il rito quanto la Sacra Scrittura proclamata si presentano come un'unità di elementi verbali e non verbali, ma indicano un altro rapporto fondamentale: gli eventi della salvezza che Dio ha compiuto e nei quali si è rivelato al mondo giungono a noi nella testimonianza canonica della Sacra Scrittura e nell'azione memoriale della liturgia ${ }^{67}$. Per questo, Sacra Scrittura e rito sono due elementi imprescindibili per l'esperienza della fede e sono tra loro inseparabili ${ }^{68}$.

La prima indicazione che viene data riguarda la valorizzazione del testo biblico; nelle celebrazioni si dovrà predisporre una lettura più abbondante, più varia e più appropriata. Questa disposizione prevista al paragrafo primo del numero in questione ha provocato nella successiva riforma liturgica una maggiore valorizzazione dato all'ascolto della Parola di Dio, che risulta essere estremamente ricca e orientata a presentare con maggiore ampiezza i tratti della storia della salvezza ${ }^{69}$. Inoltre, ogni rituale riformato dei sacramenti e dei sacramentali presenta un lezionario proprio, che rappresenta una via fondamentale per esplicitare il senso teologico ed esistenziale della celebrazione stessa. Questo orientamento risulta maggiormente comprensibile se si tiene presente che, per ragioni storiche, nelle celebrazioni liturgiche come si svolgevano prima del Vaticano II la Sacra Scrittura aveva una presenza molto più sacrificata: i testi biblici erano in minore qualità, e talora ricorrevano più volte identici ${ }^{70}$.

La seconda indicazione riguarda il compito della predicazione che è definita come "parte dell'azione liturgica" e pienamente integrata nella struttura celebrativa, e deve trovare in essa anche la sua fonte attingendo alla Sacra Scrittura e alla liturgia stessa. Propriamente non sono da considerare due fonti che forniscono temi distinti, ma due vie che consentono

${ }^{67}$ Cf. T. Federici, Parola di Dio e liturgia della Chiesa nella Costituzione «Sacrosanctum Concilium», in: Costituzione liturgica «Sacrosanctum Concilium». Studi, a cura di Congregazione per il Culto Divino Roma 1986, pp. 269-278.

${ }^{68}$ Cf. J. Daniélou, Bibbia e liturgia: la teologia biblica dei sacramenti e delle feste secondo i Padri della Chiesa, Milano 1958, pp. 53-91; R. Taft, Cosa fa la liturgia? Verso una soteriologia della celebrazione liturgica. Alcuni testi, “Communio" 21 (1993), pp. 8-25.

${ }^{69}$ Cf. C. M. Martini, La Parola di Dio alle origini, Roma 1980, p. 8.

${ }^{70}$ Cf. E. Cattaneo, La riforma liturgica del Vaticano II: riflessione storica, Milano 1976, pp. 68-80. 
di raggiungere lo stesso oggetto: la predicazione. Infatti, è l’annuncio delle opere di salvezza che nella Sacra Scrittura sono attestate e che nella liturgia sono rese in modo particolare presenti e operanti $\mathrm{i}^{71}$. Volutamente, però, il testo non aggiunge altro sul tema della predicazione rimandando a quanto si potrà dire in altri luoghi più adatti. Viene però raccomandato che il ministero della predicazione sia adempiuto con fedeltà e nel debito modo ${ }^{72}$.

La terza indicazione insiste soprattutto sulla necessità di promuovere una catechesi più direttamente liturgica, nella consapevolezza che la vita liturgica ha bisogno di essere sostenuta da un approfondimento catechistico e, nello stesso tempo, costituisce per quest'ultimo una fonte a cui attingere per sviluppare un'autentica spiritualità della vita cristiana. Su questa linea, e in relazione più esplicita con la questione della riforma, il testo invita a prevedere nei riti stessi, dove e quando si ritenga necessario, lo spazio per brevi didascalie, affidate al sacerdote o ad altri ministri ${ }^{73}$.

Lultima indicazione, che viene data non era prevista nello schema presentato in aula conciliare ma fu sollecitata dall'intervento di alcuni Padri. Il testo, completamente nuovo, risulta anche abbastanza innovativo nei contenuti e nel linguaggio. Esso, infatti, auspica che si promuovano le celebrazioni della Parola di Dio per vari momenti dell'anno liturgico. Questa disposizione costituisce una novità rispetto al passato poiché veniva proposto un atto di culto incentrato sulla Parola di Dio e tale atto era chiamato con il termine "celebrazione". Secondo il testo conciliare le suddette celebrazioni possano essere valorizzate in modo particolare nelle comunità in cui manca il presbitero. Proprio per questa ragione il testo richiama la possibilità che tali celebrazioni siano dirette dal diacono e da altra persona delegata dal vescovo.

Dalla lettura del numero 35 della Costituzione sulla liturgia Sacrosanctum Concilium, risulta che tale documento conciliare non ha come obiettivo l'individuazione del ministero diaconale, ma semplicemente, nel voler risolvere la dualità tra riti e Parola di Dio, auspica una armo-

${ }^{71}$ Cf. Sacrosanctum Concilium, n. 7, AAS 56 (1964), p. 101.

${ }^{72}$ Cf. Z. Alszeghy, M. Flick, Il problema teologico della predicazione, "Gregorianum” XL (1959), pp. 671-744.

${ }^{73}$ Cf. R. Malcherek, Gemeinschaft von Gott und den Menschen. Überlegungen zur Liturgie als gottmenschlicher Dialog nach der Liturgiekonstitution des II. Vatikanischen Konzil, "Ecclesia orans" 18 (2001), pp. 237-268. 
nizzazione maggiore attraverso "celebrazioni" della Parola che possano essere svolte anche da diaconi ${ }^{74}$. Questo dato va letto innanzitutto come un segnale da parte del Concilio della volontà di ripresentare in modo nuovo il diaconato, parlando esplicitamente di tale ministero. Inoltre si delinea, prima ancora che fosse individuato uno statuto diaconale, un primo compito: la presidenza delle celebrazioni della Parola di Dio. Tale presidenza, tuttavia, è condizionata da un elemento: che tali celebrazioni avvengano dove non vi è la possibilità di avere un sacerdote, per cui non si possa celebrare l'Eucaristia, soprattutto nelle feste più solenni e nel tempo di Avvento e Quaresima ${ }^{75}$. Per cui le celebrazioni della Parola di Dio, sono da promuovere soprattutto in mancanza della celebrazione dell'Eucaristia. Il diacono ha il compito di presiedere queste celebrazioni dove si possa dare il nutrimento, almeno della Parola, qualora manchi la possibilità del nutrimento eucaristico ${ }^{76}$. In ultimo va osservato che il Concilio, non assegna la prerogativa della presidenza esclusivamente al diacono ma apre ad altre possibilità dicendo "o altra persona degna delegata dal vescovo". Questa specificazione rileva in prima battuta che lobiettivo da raggiungere è l'edificazione delle comunità ecclesiali attraverso l'annuncio e l'ascolto comunitario della Parola di $\mathrm{Dio}^{77}$, e che tale obiettivo può essere raggiunto attraverso una ministerialità "allargata" a seconda del mandato che il Vescovo stesso può porre in essere ${ }^{78}$. Si tratta di una ministerialità "allargata" nel senso che non si specifica se si tratti di un ministro determinato da criteri di sesso, età o statuto personale

${ }^{74}$ Cf. O. De Cagny, Le diacre dans la liturgie romaine: serviteur de l'évêque, serviteuue du peuple chrétien, "Communio" 26 (2001), pp. 53-63.

${ }^{75}$ Cf. A. Nocent, Il tempo pasquale, in: L'anno liturgico. Storia, teologia e celebrazione, a cura di M. Augé, A. J. Chupungco, A. Nocent, M. Roonney, I. Scicolone, A. M. Triacca, Genova-Milano 1988, pp. 127-150.

${ }^{76}$ Cf. R. Civil, La liturgia e le sue leggi, in: La liturgia, momento nella storia della salvezza, a cura di B. Neunheuser, S. Marsili, M. Augé, R. Civil, Genova-Milano 1974, pp. 195-198.

77 Cf. A. J. Chupungco, Ladattamento dei sacramentali. Principi e possibilità, in: I sacramentali e le benedizioni, a cura di I. Scicolone, A. Noncet, M. Augé, L. Chengalikavil, A. M. Triacca, P. Rouillard, D. Sartore, A. J. Chupungco, Genova-Milano 1989, pp. 261-263.

78 Cf. P. M. Gy, La fonction des laics dans la liturgie, "La Maison-Dieu” 40 (1985), pp. $43-54$. 
o funzionale particolare ${ }^{79}$. La sua individuazione rientra nella premura del vescovo e nella sua attività di discernimento avendo come scopo l’edificazione della comunità nella Parola.

\subsection{LA COSTITUZIONE DOGMATICA SULLA CHIESA LUMEN GENTIUM}

La Costituzione dogmatica sulla Chiesa Lumen gentium, dedica il capitolo III alla costituzione gerarchica della Chiesa. Alla fine del capitolo, al n. 29 parla del diaconato come "il ponte" fra i vescovi e presbiteri da una parte, e il resto del popolo di Dio dall'altra ${ }^{80}$. Il testo conciliare così recita:

In gradu inferiori hierarchiae sistunt Diaconi, quibus «non ad sacerdotium, sed ad ministerium» manus imponuntur. Gratia etenim sacramentali roborati, in diaconia liturgiae, verbi et caritatis Popula Dei, in communione cum Episcopo eiusque presbyterio, inserviunt. Diaconi est, prout ei a competenti auctoritate assignatum fuerit, solemniter baptismum administrare, Eucharistiam servare et distribuere, matrimonio Ecclesiae nomine adsistere et benedicere, Viaticum moribundis deferre, fidelibus sacram legere Scripturam, populum instruere et exhortari, fidelium cultui et orationi praesidere, sacramentalia ministrare, ritui funeris ac sepulturae praeesse. Caritatis et administrationis officiis dediti, meminerint Diaconi moniti Beati Polycarpi: «Misericordes, seduli, incedentes iuxta veritatem Domini, qui omnium minister factus est ${ }^{81}$.

Innanzitutto, il diaconato viene presentato come "grado inferiore" della gerarchia, e questo per la grazia dell'imposizione delle mani. Questa posizione si inserisce nel solco della Tradizione in rapporto al vescovo, al quale il diacono è sottomesso. Nella stessa celebrazione eucaristica egli non ha né la possibilità di presiedere né quella di consacrare il pane e il vino. Infine viene affermato che il diacono è ordinato "non ad sacerdotium, sed ad ministerium" 82 .

79 Cf. G. Zambon, Laicato e tipologie ecclesiali: ricerca storica sulla teologia del laicato in Italia alla luce del Concilio Vaticano II (1950-1980), Roma 1996, pp. 409-418.

${ }^{80}$ Cf. E. Petrolino, Il Concilio Vaticano II e il diaconato, p. 31.

${ }^{81}$ Sacrosanctum Concilium Oecumenicum Vaticanum II, Constitutio dogmatica de Ecclesia Lumen gentium, 21.11.1964, n. 29, AAS 57 (1965), p. 36.

${ }^{82}$ Cf. P. De Clerck, Note sur l'expression "Non ad sacerdotium sed ad ministerium", "La Maison-Dieu" 63 (2007), pp. 53-70. 
I Padri conciliari hanno utilizzato una formula tratta dalle $\mathrm{Co}$ stitutiones Ecclesiae aegyptiacae del IV secolo ${ }^{83}$ ma presente pure nella Didascalia de duodecim Apostoli di questo stesso secolo ${ }^{84}$ e negli Statuta Ecclesiae Antiqua di V secolo ${ }^{85}$. Questa formula compendia un testo ancora più antico tratto dalla Traditio apostolica d'Ippolito di Roma dell'inizio del III secolo ${ }^{86}$ che diceva "ad ministerium episcopi"

La modalità espressiva scelta dai Padri riprende la distinzione tra "sacerdozio" e "ministero", trasmessa dalle Costitutiones Ecclesiae aegyptiacae, citato in nota nel testo conciliare. Il diaconato è da comprendere, in tal senso, all'interno dell'unità del Sacramento dell'Ordine. L'espressione ministerium episcopi non individua il servizio che ha per oggetto il vescovo, altrimenti sembrerebbe che i diaconi siano semplicemente dei servitori del vescovo. Essi non sono al "suo" servizio, ma sono destinati al ministero di cui egli è il soggetto d’attribuzione. Per cui, i diaconi sono ordinati per il ministero di cui il vescovo è il titolare, nel senso di autore, auctor, colui che è garante ${ }^{88}$. Il vescovo è incaricato di servire la comunità affinché sia custodita nella comunità la fedeltà alla fede degli Apostoli ${ }^{89}$, e in questo senso né promuove la sua stessa identità apostolica. Il vescovo, in primo luogo, come colui che presiede la Chiesa, in quel particolare luogo, esercita questo ministero apostolico verso la comunità di cui egli è il primo servitore. I diaconi collaborano a questo ministero ${ }^{90}$.

${ }^{83}$ Cf. Constitutiones Ecclesiae aegyptiacae, III, 2, in: Didascalia et Constitutiones Apostolorum, vol. II, ed. F. X. Funk, Paderborn 1905, p. 103.

${ }^{84}$ Cf. Didascalia de duodecim Apostoli, in: Didascalia et Constitutiones apostolicae, vol. I, ed. F. X. Funk, Paderborn 1905, pp. 289-290.

${ }^{85}$ Cf. Statuta Ecclesiae Antiqua, in: Concilia Galliae a. 314-505, 148, ed. C. Munier, Turnholt 1963, p. 171.

${ }^{86}$ Cf. Ippolito Romanus, Traditio apostolica, 8, in: Hippolyte de Rome. La Trdition Apostolique, ed. B. Botte, SCh, vol. 11 bis, Paris 1968, 57.

${ }^{87}$ Cf. A. Borras, Il diaconato vittima della sua novità?, p. 50; J. Zizioulas, L’Eucaristie, l'evêque et l'Eglise durant les premiers siècles, Paris 1994, pp. 191-240.

${ }^{88}$ Cf. A. Borras, Il diaconato vittima della sua novità?, p. 51; id., Le diaconat exercé en permanence: restauration ou retablissement?, "Nouvelle Revue Théologique" 118 (1996), pp. 817-838.

${ }^{89}$ Cf. Y. M. Congar, Ministeri e comunione ecclesiale, Bologna 1973. pp. 45-80.

${ }^{90}$ Cf. D. Gonneaud, Pour le quarantiènne anniversaire du rétablissement de lordo diaconal: réflexions autour d'une maxime doctrinale, "Nouvelle Revue Théologique" 126 (2004), pp. 556-557. 
Lordinazione conferisce la grazia per servire la Chiesa attraverso un effetto istituente e abilitante. Pertanto, considerando l'imbarazzo di dire teologicamente qualcosa del diaconato, i Padri conciliari avevano fatto appello alla categoria del ministero. Per esprimere l'originalità della sua sacramentalità, ci si deve accontentare di compararlo con quello che si dice degli altri ordini, dell'episcopato e del presbiterato, e cioè che l'ordinazione diaconale conferisce la grazia dello Spirito Santo per esercitare un ministero. Si rimane sobri nel dire di quale ministero si tratti. In ogni caso non può essere il ministero pastorale di presidenza della Chiesa e della sua Eucaristia ${ }^{91}$. Per cui il diacono non è ordinato per presiedere e consacrare l'Eucaristia, cosa che contraddistingue il compito ministeriale del sacerdote, ma per il servizio del Popolo di Dio, ulteriormente specificato e caratterizzato, nella Relatio $^{92}$ che accompagna il testo, come servitium caritatis, in comunione con il vescovo e il suo presbiterio. Lantica formula ripresa dagli Statuta Ecclesiae Antiqua non è tuttavia aliena da ogni ambiguità, soprattutto se riportata alla distinzione di essenza e non meramente di grado tra sacerdozio comune dei fedeli e sacerdozio ministeriale o gerarchico a cui fa riferimento l'articolo 10 della Costituzione Lumen gentium e alla giustapposizione netta che sembra istituire tra sacerdozio e ministero ${ }^{93}$.

I Padri conciliari si sono limitati a riconoscere che i diaconi sono "gratia enim sacramentali roborati". Nella Relatio della Commissione dottrinale che accompagna il testo della Costituzione Lumen gentium, si precisa che tale cautela nell'affermare la sacramentalità del diaconato è volta a non offendere e a non condannare coloro che sostenevano l'opinione minoritaria contraria ${ }^{94}$. Beyer mette in evidenza che sulla natura sacramentale del diaconato regnasse una notevole incertezza dottrinale anche tra i Padri conciliari ${ }^{95}$. Infatti il Concilio di Trento, definendo

${ }^{91}$ Cf. A. Borras, Il diaconato vittima della sua novità?, p. 99.

92 Cf. Relatio, in: Acta Synodalia, III, III, Città del Vaticano 1973, pp. 65-68.

93 Cf. H. Vorgrimler, Commento allarticolo 29 di Lumen gentium, in: La gerarchia nella Chiesa. Commento al Capitolo III di Lumen gentium, a cura di K. Rahner, Brescia 2008, p. 84.

${ }^{94}$ Cf. Acta Synodalia, III, I, p. 260. A tal riguardo si veda: G. Philips, La Chiesa e il suo mistero. Storia, testo e commento della Lumen Gentium, Milano 1975, p. 329.

95 Cf. J. Beyer, De diaconatu animadversiones, "Periodica” 69 (1968), pp. 141-160. 
dogmaticamente la sacra ordinazione, come vero sacramento, non aveva fatto riferimento esplicito al diaconato e quindi non è del tutto certo che le affermazioni dogmatiche di Trento sulla sacramentalità e sul carattere sacramentale del sacerdozio (al quale esso si riferisce direttamente) comportino anche una intenzionalità conciliare di definire dogmaticamente la sacramentalità del diaconato ${ }^{96}$. Nella Relazione della Commissione dottrinale, lindole sacramentale del diaconato viene fondata sulla Tradizione e il Magistero, citando in particolare la Costituzione Apostolica Sacramentum Ordinis di Pio XII, del 30 novembre $1947^{97}$, con quale si era provveduto a stabilire e regolare la materia e la forma del Sacramento dell'Ordine, nei tre gradi dell'episcopato, del presbiterato e del diaconato ${ }^{98}$.

In compenso, oggi il riconoscimento della sacramentalità è divenuto una dottrina comune, ma una dottrina certa nella teologia cattolica. Soprattutto nel Magistero dei Pontefici successivi al Concilio, si afferma la sacramentalità come indicato dal Motu proprio Sacrum diaconatus ordinem del 1967, dal Motu proprio Ad pascendum del 1972, dal Direttorio per il ministero e per la vita dei diaconi permanenti del 1998, dal Codice di Diritto Canonico del 1983, dal Catechismo della Chiesa Cattolica del 1992 e la sua edizione definitiva del 1997.

Quindi si menzionano i tre ambiti di esercizio del servizio diaconale fra loro strettamente legati: alla liturgia, coronamento e fonte delle altre funzioni, seguono il servizio della Parola e la carità, il tutto finalizzato e autenticato da uno spirito di comunione col vescovo e il presbiterio diocesano $^{99}$. In altre parole, si potrebbe dire che in questo punto è specificato in che modo viene realizzata dai diaconi la partecipazione ai tria munera, che seppur col battesimo appartengano a tutti i cristiani, sono esercitati in modo speciale da chi nella comunità cristiana viene investito di un

${ }^{96}$ Cf. Commissione Teologica Internazionale, Il diaconato. Evoluzione e prospettive, in: Nuovo Enchiridion sul Diaconato. Le fonti e i documenti ufficiali della Chiesa, a cura di E. Petrolino, Città del Vaticano 2016, IV, II, 3, p. 569.

${ }_{97}$ Cf. Pius XII, Constitutio Apostolica de Sacris Ordinibus Diaconatus, Presbyteratus et Episcopatus Sacramentum Ordinis, AAS 40 (1948), pp. 5-7.

${ }_{98}$ Cf. Acta Synodalia, III, I, p. 260.

99 Cf. C. M. Martini, La comunione presbiterale, Milano 2015, pp. 49-108; G. Irti, La pericoresi trinitaria: modello e fondamento della comunità evangelizzatrice nelledificazione delle chiese locali, Roma 2004, pp. 107-111. 
speciale munus $^{100}$. In tal caso si parla semplicemente di "diaconia”. Ancora una volta il Concilio propone un testo sobrio, evidentemente, frutto di dibattiti, che in definitiva non spiega lo statuto personale e funzionale di tale ministero. E' necessario ancora di continuare a leggere non solo quanto a tal riguardo è affermato dalla Costituzione Lumen gentium, ma anche nell'intera partitura del Concilio. Quanto alle modalità concrete, il testo nota che l'autorità competente che ha il compito di dare disposizioni sulle attività del diacono ${ }^{101}$. Dieci compiti liturgici vengono menzionati: l'amministrazione solenne del battesimo; la conservazione e la distribuzione dell'Eucaristia; l'assistenza e la benedizione del matrimonio; portare il Viatico ai malati; leggere la Sacra Scrittura ai fedeli e la conseguente predicazione; la presidenza del culto e della preghiera dei fedeli; l'amministrazione dei sacramentali e la presidenza delle esequie e della sepoltura. Si nota che lenumerazione dei compiti liturgici non è data nella Costituzione sulla liturgia Sacramentum Concilium, ma nella Costituzione sulla Chiesa. Subito dopo tali compiti si dichiara che i diaconi sono altresì dedicati agli uffici di carità e di assistenza. Loro nello svolgimento di tali uffici devono essere secondo San Policarpo "misericordiosi, attivi, camminare secondo la verità del Signore, il quale si è fatto servo di tutti” 102 .

Il testo conciliare nella seconda parte aggiunge:

Cum vero haec munera, ad vitam Ecclesiae summopere necessaria, in disciplina Ecclesiae latinae hodie vigenti in pluribus regionibus adim-

100 Cf. D. M. Leclair, The Deacon's participation in the Tria Munera in the Latin and Ukranian Catholic Churches: A historical-canonical Analysis, Ottava 2008, pp. 190-211; J. Miñambres, Diritto canonico e servizio della carità, Milano 2008, pp. 166-168.

101 Cf. E. Petrolino, Il Concilio Vaticano II e il diaconato, p. 33.

102 Il brano citato nella Costituzione Lumen gentium è tratto dalla Seconda lettera ai Filippesi di San Policarpo che nella sua interezza dice: "Così i diaconi siano irreprensibili di fronte alla sua giustizia come servitori di Cristo e di Dio e non degli uomini: non calunniatori, non doppi nella parola, non avari, puri in ogni cosa, pieni di misericordia, zelanti, camminando secondo la carità del Signore che si fece servitore di tutti. Se a lui piaceremo in questo modo otterremo quello futuro. Egli ci ha promesso di risuscitarci dai morti e se vivremo in maniera degna di lui, abbiamo cioè la fede, regneremo con lui" (Policarpo, Secundus litterae ad Philippenses, in: Die Apostolischen Väter. Griechisch-deutsche parallelausgsche, vol. I, ed. F. X. Funk, K. Bihlmeyer, M. Whittaker, Tübingen 1992, p. 300. 
pleri difficulter possint, Diaconatus in futurum tamquam proprius ac permanens gradus hierarchiae restitui poterit. Ad competentes autem varii generis territoriales Episcoporum coetus, approbante ipso Summo Pontifice, spectat decernere, utrum et ubinam pro cura animarum huiusmodi Diaconos institui opportunum sit. De consensu Romani Pontificis hic Diaconatus viris maturioris aetatis etiam in matrimonio viventibus conferri poterit, necnon iuvenibus idoneis, pro quibus tamen lex coelibatus firma remanere debet ${ }^{103}$.

Si dice che "il diaconato potrà in futuro essere ristabilito come proprio e permanente grado della gerarchia". Viene individuato innanzitutto il motivo di tale scelta, che è essenzialmente di ordine ecclesiale e quindi pastorale ovvero il dato che questi uffici sono necessari alla vita della Chiesa e che in molti regioni difficilmente possono essere esercitati. Lindividuazione di altri ministri proposti a tali uffici, diremmo, a fianco a coloro che già li svolgono, ovvero i sacerdoti, andrebbe a sopperire a questa carenza in quelle regioni in cui tale servizio pastorale è mancante. In ogni regione è lasciata la determinazione di poter dare ai diaconi la "cura delle anime" sulla base di quanto deciso dei raggruppamenti territoriali dei vescovi ${ }^{104}$ e con l'approvazione dello stesso Sommo Pontefice. Cosa si intende per "cura delle anime"? Si potrebbe intendere la guida di una comunità cristiana? Di fatti, ancora una volta il testo appare sobrio. Potrebbe lasciare intendere che si parli di guida della comunità, in quanto è subordinata ad un duplice assenso: dei vescovi appartenenti al raggruppamento di Chiese particolari, e al Romano Pontefice. Tuttavia la lista circoscritta di funzioni liturgiche sopra descritta, confermerebbe il dato che non si possa parlare di "cura pastorale" così come la conosciamo attribuita al sacerdote-parroco ${ }^{105}$. Ancora una volta abbiamo bisogno di continuare la nostra analisi per determinare lo statuto del diacono e a quale statuto funzionale egli sarà abilitato.

${ }^{103}$ Lumen gentium, n. 29, p. 36.

${ }^{104}$ Cf. J. Manzanares, De conferentiis episcopalibus post decem annos a Concilio Vaticano II, "Periodica" 64 (1975), pp. 596-598; P. Gouyon, Les relations entre le diocèse et la conférence episcopale, "Lannée canonique" 22 (1978), pp. 1-23; G. Feliciani, Le conferenze episcopali, Bologna 1974, pp. 353-359.

${ }^{105}$ Cf. S. Zardoni, I diaconi nella Chiesa. Ricerca storica e teologica sul diaconato, Bologna 1990, p. 54. 
Si dice "restitui poterit", utilizzando così il verbo restituere, ovvero "ripristinare", più che "restaurare", relativamente alla decisione della Chiesa latina; mentre in relazione all'azione delle Conferenze episcopali si dice "istitui sit" quindi il verbo instituere, nel senso di istituire ${ }^{106}$. In ogni caso lopera delle Conferenze episcopali è intesa come un "decernere". Ovvero un atto di discernimento ecclesiale ${ }^{107}$.

Per completare la disposizione circa l'istituzione di tali diaconi si dice:

De consensu Romani Pontificis hic Diaconatus viris maturioris aetatis etiam in matrimonio viventibus conferri poterit, necnon iuvenibus idoneis, pro quibus tamen lex coelibatus firma remanere debet ${ }^{108}$.

Si può dire che la vera innovazione del Concilio è la previsione di diaconi sposati ${ }^{109}$. Infatti nelle disposizioni storicamente precedenti la legge del celibato era richiesta a tutti i chierici, e per trovare dei diaconi sposati, probabilmente bisogna risalire ai primissimi secoli, quando non solo i diaconi, ma anche presbiteri e vescovi avevano una sposa ${ }^{110}$.

Si parla ancora dei diaconi nel capitolo $\mathrm{V}$, dove è dato particolare risalto alla vocazione alla santità. Il numero 41, passa in rassegna le varie

106 Cf. S. Noceti, La costituzione gerarchica della Chiesa e in particolare l'episcopato art. cit., p. 310 .

107 Cf. G. Feliciani, Corresponsabilità ecclesiale nella struttura gerarchica della Chiesa, in: Comunione ecclesiale e strutture di corresponsabilità: dal Vaticano II al nuovo Codice di diritto canonico, a cura di J. Beyer, G. Feliciani, H. Müller, Roma 1990, pp. 37-50; I. Siviglia, Il discernimento ecclesiale, "Ho Théologos" 13 (1995), pp. 32-41; E. Castellucci, I «segni dei tempi» e la lettura ecclesiale della società, "Parole spirito e vita" 71 (2015), pp. 197-198; F. Iannone, Per una rinnovata lettura ecclesiale dei segni dei tempi, "Credere oggi" 37 (2017), pp. 85-97.

${ }^{108}$ Lumen gentium, n. 29, p. 36.

109 Cf. M. Cancouët, B. Violle, Les diacres, Paris 1990, pp. 98-102.

110 Cf. A. M. Stickler, La continenza dei diaconi specialmente nel primo millennio della Chiesa, "Salesianum" 26 (1964), pp. 275-302; C. Cochini, Il celibato sacerdotale nella tradizione primitiva della Chiesa, in: Identità e missione del sacerdote, a cura di G. Pittau, C. Sepe, Roma 1994, pp. 166-189; G. Ramboldi, Sacerdozio di Cristo e sacerdozio ministeriale nella Chiesa. Alcuni problemi di teologia sacerdotale, in: Sacerdozio e celibato. Studi storici e teologici, a cura di J. Coppens, Milano 1975, pp. 412-417. 
vocazioni nella Chiesa e per tutte, il testo, cerca di declinare la modalità propria per vivere la santità. Dopo aver parlato dei pastori, ovvero dei vescovi e dei sacerdoti, si parla dei ministri di ordine inferiore, fra cui e primi fra tutti i diaconi, che partecipano alla missione e alla grazia del Cristo, sommo Sacerdote:

Missionis autem et gratiae supremi Sacerdotis peculiari modo participes sunt inferioris quoque ordinis ministri, imprimis Diaconi, qui mysteriis Christi et Ecclesiae servientes, ab omni vitio puros se custodire atque Deo placere et omne bonum coram hominibus providere debent (cfr. 1 Tim 3,8-10 et 12-13). Clerici, qui a Domino vocati et in partem Eius sepositi, sub vigilantia Pastorum ad officia ministrorum se praeparant, mentes et corda sua tam praeclarae electioni conformare tenentur, in oratione assidui, amore ferventes, quaecumque sunt vera, iusta et bonae famae cogitantes, omnia in gloriam et honorem Dei perficientes. Quibus accedunt illi a Deo electi laici, qui, ut plene se dedant apostolicis operibus, ab Episcopo vocantur et in agro Domini cum multo fructu laborant ${ }^{111}$.

I ministri di ordine inferiore "partecipano alla missione e alla grazia del sommo Sacerdote, secondo la propria specificità". Si tratta di diaconi, chierici, laici dedicati pienamente alle opere apostoliche ${ }^{112}$. Mentre per questi laici il testo non offre altre indicazioni, esplicita per contro il dovere dei diaconi a "mantenersi puri da ogni vizio, piacere a Dio e provvedere ad ogni opera buona davanti agli uomini", citando in tal modo Ignazio nella lettera ai Tralliani ${ }^{113}$.

Il dettato previsto dalla Costituzione dogmatica sulla Chiesa costituisce un importante punto di riferimento per quanto attiene l'individuazione dell'identità diaconale. Si può dire che costituisce l'espressione più precisa sullo statuto personale del diacono e del suo conseguente statuto funzionale. Di conseguenza costituisce il più importante riferimento per poter definire e quindi capire il diaconato nella Chiesa contemporanea.

111 Lumen gentium, n. 41, p. 46.

112 Cf. S. Mazzolini, Vocazione universale alla santità nella Chiesa, in: Commentario ai documenti del Vaticano II, a cura di S. Noceti, R. Repole, Roma 2006, p. 369.

113 Ignatius Antiochenus, Litteras ad Trallenses II, 1-3, ed. J. P. Migne, Patrologiae cursus completus, pp. 781-782. 


\subsection{IL DECRETO SULLE CHIESE ORIENTALI ORIENTALIUM ECCLESIARUM}

Il Decreto sulle Chiese Orientali, Orientalium Ecclesiarum, del 21 novembre 1964, appoggiandosi ad una serie di Concilii e Sinodi Orientali citati in nota, nel numero 17 , auspica che venga ristabilito il diaconato permanente laddove esso fosse caduto in disuso ${ }^{114}$.

Ut antiqua sacramenti Ordinis disciplina in Ecclesiis Orientalibus iterum vigeat, exoptat haec Sancta Synodus, ut institutum diaconatus permanentis, ubi in desuetudinem venerit, instauretur. Quoad subdiaconatum vero et Ordines inferiores eorumque iura et obligationes, provideat Auctoritas legislativa uniuscuiusque Ecclesiae particularis ${ }^{115}$.

\subsection{IL DECRETO SULLA MISSIONE PASTORALE DEI VESCOVI NELLA CHIESA CHRISTUS DOMINUS}

Il Decreto sulla missione pastorale dei vescovi nella Chiesa Christus Dominus, del 28 ottobre 1965, nella parte riguardante la missione santificatrice dei vescovi nel numero 15 , ricorda che nell'esercizio delle loro potestates, i presbiteri e i diaconi dipendono dai vescovi, i quali "plenitudine Sacramenti Ordinis gaudent"116. Si ribadisce coerentemente con il dettato della Costituzione Lumen gentium nel numero 29 che i diaconi in unione col vescovo ed al servizio del suo presbiterio sono destinati al ministero del Popolo di Dio:

In exercendo suo munere sanctificandi memores sint Episcopi se ex hominibus assumptos esse et pro hominibus constitui, in iis quae sunt ad Deum, ut offerant dona et sacrificia pro peccatis. Episcopi enim plenitudine Sacramenti Ordinis gaudent et ab ipsis in exercenda sua potestate

114 Cf. G. Bruni, Quale ecclesiologia? Cattolicesimo e ortodossia a confronto: il dialogo ufficiale, Milano 1999, pp. 23-30.

115 Sacrosanctum Concilium Oecumenicum Vaticanum II, Decretum de Ecclesiis orientalibus catholicis Orientalium Ecclesiarum, 21.11.1964, n. 17, AAS 57 (1965), pp. 81-82.

116 Cf. D. L. Gelpi, Committed Worship: The sacraments of ongoing conversion, Collegeville 1993, pp. 110-115; J. S. Exparza, The Diaconate: a challenge from the past, Bloomgton 2009, pp. 36-40. 
pendent tum presbyteri, qui quidem, ut Ordinis episcopalis providi sint cooperatores, et ipsi consecrati sunt veri Novi Testamenti sacerdotes, tum diaconi, qui ad ministerium ordinati populo Dei in communione cum Episcopo eiusque presbyterio inserviunt; ipsi itaque Episcopi praecipui sunt dispensatores mysteriorum Dei, sicut et totius vitae liturgicae in Ecclesia sibi commissa moderatores, promotores atque custodes ${ }^{117}$.

\subsection{IL DECRETO SULL'ATTIVITÀ MISSIONARIA DELLA CHIESA AD GENTES}

Nel Decreto sull'attività missionaria della Chiesa Ad gentes, del 7 dicembre 1965, al numero 15 si parla della situazione e dello sviluppo delle comunità cristiane ${ }^{118}$. A tal fine, esso sottolinea l'importanza dei vari tipi di ministeri che tutti debbono promuovere e rispettare:

Iamvero, ad Ecclesiae plantationem et ad incrementum communitatis christianae necessaria sunt varia ministeria, quae vocatione divina ex ipsa fidelium congregatione suscitata, ab omnibus diligenti cura sunt fovenda atque colenda; inter quae habentur munera sacerdotum, diaconorum et catechistarum, atque actio catholica. Item Religiosi et Religiosae ad Regnum Christi in animis radicandum et corroborandum illudque ulterius dilatandum sive oratione; sive actuosa opera indispensabile praestant officium ${ }^{119}$.

Ma il punto più rilevante sul diaconato è il numero 16, dedicato all'emergenza di un clero indigeno. Infatti, la Chiesa si rallegra per il sorgere di nuove vocazioni in mezzo ai popoli convertitisi in epoche più

117 Sacrosanctum Concilium Oecumenicum Vaticanum II, Decretum de pastorali Episcoporum munere in Ecclesia Christus Dominus, 28.10.1965, n. 15, AAS 58 (1966), pp. 679-680.

118 Cf. B. Mondin, La Chiesa Sacramento d'amore: trattato di ecclesiologia, Bologna 1993, pp. 339-349; W. Insero, La chiesa è "missionaria per sua natura" (AG 2); origine e contenuto dellaffermazione conciliare e la sua recezione nel dopo Concilio, Roma 2007, pp. 34-51; A. M. Henry, Mission d'hier, mission de demain, in: Lactivité missionnaire de l'Église. Décret “Ad gentes", a cura di J. Schütter, Paris 1967, pp. 411-440; S. Karotemprel, Chiesa e missione oggi, in: Il Concilio Vaticano II: recezione ed attualità alla luce del Giubileo, a cura di R. Fisichella, Cinisello Balsamo (MI) 2000, pp. 294-317.

119 Sacrosanctum Concilium Oecumenicum Vaticanum II, Decretum de activitate missionali Ecclesiae Ad gentes, 7.12.1965, n. 15, AAS 58 (1966), p. 965. 
recenti e rafforza, alla luce di quanto espresso nei documenti conciliari, la raccomandazione ad una adeguata preparazione del clero. In tale contesto si dice:

Ubi Conferentiis Episcoporum opportunum apparuerit, ordo diaconatus ut status vitae permanens restauretur ad normam Constitutionis de Ecclesia. Iuvat enim viros, qui ministerio vere diaconali fungantur, vel verbum divinum tanquam catechistae praedicantes, vel nomine parochi et episcopi dissitas communitates christianas moderantes, vel caritatem exercentes in operibus socialibus seu caritativis, per impositionem manuum inde ab Apostolis traditam corroborari et altari arctius coniungi, ut ministerium suum per gratiam sacramentalem diaconatus efficacius expleant ${ }^{120}$.

È compito delle Conferenze episcopali la cura di valutare l'opportunità di ristabilire nella loro regione il diaconato permanente, qui descritto come uno "status vitae permanens", definendo, in un certo modo uno statuto personale, ovvero uno stato che non è ad tempus e non attiene semplicemente all'ambito funzionale ma riguarda un modo di esistere, una concreta vocazione. Il testo sottolinea l'utilità, non la necessità, di ricevere l'imposizione delle mani per quegli uomini (viros) che già esercitano il ministero di diacono, o perché come catechisti predicano la parola di Dio, o perché a nome del parroco e del vescovo sono a capo di comunità cristiane lontane, o perché esercitano la carità attraverso opere sociali e caritative $^{121}$. Il testo sottolinea l'utilità di una ordinazione che fortifica e unisce più strettamente all'altare, e che possa realmente unire l'altare all'azione pastorale ${ }^{122}$.

Nella discussione che tale documento porta, e a quanto altri autori riferiscono a riguardo della sobrietà anche di esso ${ }^{123}$, è possibile, semplicemente, rilevare che il testo propone un criterio di individuazione di coloro che possano essere ammessi al diaconato: uomini che già eserci-

${ }^{120}$ Ibidem, n. 16, p. 967.

${ }^{121}$ Cf. S. Zardoni, I diaconi nella Chiesa. Ricerca storica e teologica sul diaconato, p. 55 , nota 68 .

122 Cf. E. Petrolino, Il Concilio Vaticano II e il diaconato, p. 35, nota 4.

123 Cf. R. Coronelli, L'identità e la specificità del ministero diaconale, "Quaderni della Mendola”, n. 19, Milano 2011, pp. 119-156. 
tino, in qualche modo, la diaconia. Tale annotazione si trova nel Decreto sullattività missionaria della Chiesa Ad gentes, per cui potremmo dire che si riferisce a Chiesa di recente evangelizzazione, ma cosa intendiamo con "recente evangelizzazione", le Chiese sottoposte a Propaganda fide? Per cui la disposizionale conciliare potrebbe essere applicabile per l'individuazione di candidati al diaconato. Resta in piedi la costatazione che neanche questo testo ha chiarificato lo statuto personale e funzionale del diaconato permanente.

Un'ulteriore obiezione potrebbe essere: a cosa abilita tale Sacramento, se di fatti si continua a fare quello che si poteva e si faceva già prima? Di fatti col Battesimo, si viene costituiti persona nella Chiesa, e l'effetto visibile di tale incorporazione è la partecipazione all'Eucaristia; col Matrimonio, gli sposi assumono obblighi e diritti reciproci che li abilitano alla convivenza e sono costituiti "piccola Chiesa domestica", col Sacerdozio, si viene abilitati a ricoprire quegli uffici che comportano la cura pastorale, e soprattutto, a celebrare l'Eucaristia e ad amministrare il Sacramento di Penitenza, seppur secondo le disposizioni previste dalla legge. In tale prospettiva quale è il cambio prodotto dalla celebrazione sacramentale? Tale obiezione permane in molti autori che ritengono necessario un ulteriore approfondimento teologico e quindi giuridico relativamente al diaconato.

\section{CONCLUSIONE}

I Padri del Concilio Vaticano II, adottando il postulato di restaurare il ministero del diacono permanente nella Chiesa latina, hanno espresso solo la volontà di ripristinare questo ministero come un livello gerarchico permanente e proprio. I documenti del Concilio Vaticano II non presentano una grande quantità di indizi che delineassero in un modo esaustivo lo statuto personale e funzionale dei diaconi permanenti. Per quanto riguarda lo statuto personale, un dato è subito chiaro, ovvero: colui che viene istituito diacono è appartenente alla gerarchia, seppur è specificato che i diaconi stanno in un grado inferiore della gerarchia col compito di servire i misteri di Dio e della Chiesa. Ad essi sono imposte le mani non per il sacerdozio, ma per il servizio. I diaconi accedono ad un vero Sacramento, infatti sostenuti dalla grazia sacramentale, nella diaconia 
della liturgia, della predicazione e della carità servono il popolo di Dio, in comunione col vescovo e con il suo presbiterio. Il dettato conciliare, che a quei tempi guardava al futuro stabiliva che il diaconato potrà essere conferito a uomini di età matura anche viventi nel matrimonio, così pure a dei giovani idonei, per i quali però deve rimanere ferma la legge del celibato. Essi devono mantenersi puri da ogni vizio, piacere a Dio e studiarsi di fare ogni genere di opere buone davanti agli uomini. Circa allo statuto funzionale dei diaconi i testi conciliari affermano che essi possono presiedere la liturgia della Parola, amministrare solennemente il battesimo, conservare e distribuire l'Eucaristia, assistere e benedire il matrimonio in nome della Chiesa, portare il Viatico ai moribondi, leggere la Sacra Scrittura ai fedeli, istruire ed esortare il popolo, presiedere al culto e alla preghiera dei fedeli, amministrare i sacramentali, presiedere al rito funebre e alla sepoltura e svolgere le opere di carità e di assistenza. Il fatto che il Concilio si sia limitato a parlare di ripristino del diaconato, come grado proprio e permanente della gerarchia, lasciando alle assemblee territoriali dei Vescovi, con l'approvazione del sommo Pontefice, la decisione ultima circa lopportunità o meno di istituire il diaconato nei propri territori, lascia pensare che la prospettiva immediata per il ripristino del diaconato permanente sia stata quella di ordine pratico-pastorale più che quella dottrinale. L'importanza data al ripristino del diaconato andrebbe valutata anche a livello simbolico: nel momento in cui si stava attuando il rinnovamento del volto e della vita della Chiesa, si sentiva il bisogno di una figura capace di esprimere la dimensione diaconica di una Chiesa serva del suo Signore e dell'umanità, attraverso la ripresa di una figura presente nella Chiesa antica e potesse rappresentare, anche in questo caso, un ritorno alle origini, alle fonti.

\section{BIBLIOGRAFIA}

Acta Synodalia Sacrosancti Concilii Oecumenici Vaticani Secundi (1962-1965), Typis Polyglottis Vaticanis 1970-1980.

Alszeghy Z, Flick M., Il problema teologico della predicazione, “Gregorianum” XL (1959), pp. 671-744.

Baumann K., Ständinger diakonat. Eine frucht des II. Vatikanus, "Roczniki Pastoralno-Katechetyczne" 60 (2013), pp. 9-17. 
Beyer J., De diaconatu animadversiones, "Periodica” 69 (1968), pp. 141-160.

Borras A., Le diaconat exercé en permanence: restauration ou retablissement?, "Nouvelle Revue Théologique" 118 (1996), pp. 817-838.

Borras A., Le diaconat au risque de sa nouveauté?, Bruxelles 2007.

Bridel C., Aux seuils de lespérance: le diaconat en notre temps, Neuchâtel-Paris 1971.

Bruni G., Quale ecclesiologia? Cattolicesimo e ortodossia a confronto: il dialogo ufficiale, Milano 1999.

Cancouët M., Violle B., Les diacres, Paris 1990.

Castellucci E., I «segni dei tempi» e la lettura ecclesiale della società, "Parole spirito e vita" 71 (2015), pp. 197-208.

Cattaneo E., La riforma liturgica del Vaticano II: riflessione storica, Milano 1976.

Chupungco A.J., Ladattamento dei sacramentali. Principi e possibilità, in: I sacramentali e le benedizioni, a cura di I. Scicolone, A. Noncet, M. Augé, L. Chengalikavil, A. M. Triacca, P. Rouillard, D. Sartore, A. J. Chupungco, Genova-Milano 1989, pp. 252-274.

Civil R., La liturgia e le sue leggi, in: La liturgia, momento nella storia della salvezza, a cura di B. Neunheuser, S. Marsili, M. Augé, R. Civil, Genova-Milano 1974, pp. 180-198.

Cochini C., Il celibato sacerdotale nella tradizione primitiva della Chiesa, in: Identità e missione del sacerdote, a cura di G. Pittau, C. Sepe, Roma 1994, pp. 166-189.

Collombert L., La rétablissement du diaconat permanent. Regards sur l'histoire, "Cahiers de l'Atelier" 491 (2001), pp. 29-42.

Commissione Teologica Internazionale, Il diaconato. Evoluzione e prospettive, in: Nuovo Enchiridion sul Diaconato. Le fonti e i documenti ufficiali della Chiesa, a cura di E. Petrolino, Città del Vaticano 2016.

Congar Y.M., Ministeri e comunione ecclesiale, Bologna 1973.

Constitutiones Ecclesiae aegyptiacae, in: Didascalia et Constitutiones Apostolorum, vol. II, ed. F. X. Funk, Paderborn 1905.

Cordes P.J., Dlaczego kapłan? Poszukiwanie odpowiedzi z Benedyktem XVI, Kielce 2009.

Coronelli R., L'identità e la specificità del ministero diaconale, "Quaderni della Mendola", n. 19, Milano 2011, pp. 119-156.

Daniélou J., Bibbia e liturgia: la teologia biblica dei sacramenti e delle feste secondo i Padri della Chiesa, Milano 1958.

De Cagny O., Le diacre dans la liturgie romaine: serviteur de l'évêque, serviteuue du peuple chrétien, "Communio" 26 (2001), pp. 53-63.

De Clerck P., Note sur l'expression "Non ad sacerdotium sed ad ministerium", "La Maison-Dieu” 63 (2007), pp. 53-70.

De la Potterie I., La lettura della Sacra Scrittura “nello Spirito", “Communio" 14 (1986), pp. 37-38.

De Lubac H., Carnets du Concile, vol. I, Paris 2007.

Didascalia de duodecim Apostoli, in: Didascalia et Constitutiones apostolicae, vol. I, ed. F. X. Funk, Paderborn 1905. 
Ditewig W.T., The contemporary renewal of the diaconate, in: The Deacon Reader, a cura di J. Keating, Leominster 2006, pp. 20-56.

Ditewig W.T., The Emerging Diaconate: Servant Leaders in a Servant Church, New York 2007.

Epagneul M.D., Du rôle du diacre dans l'Eglise d'aujourd'hui, "Nouvelle Revue Théologique" 79 (1957), pp. 153-168.

Exparza J.S., The Diaconate: a challenge from the past, Bloomgton 2009.

Falconi C., La Chiesa e le organizzazioni cattoliche in Europa, Ivrea 1960.

Federici T., Parola di Dio e liturgia della Chiesa nella Costituzione «Sacrosanctum Concilium», in: Costituzione liturgica «Sacrosanctum Concilium». Studi, a cura di Congregazione per il Culto Divino Roma 1986, pp. 269-278.

Feliciani G., Le conferenze episcopali, Bologna 1974.

Feliciani G., Corresponsabilità ecclesiale nella struttura gerarchica della Chiesa, in: Comunione ecclesiale e strutture di corresponsabilità: dal Vaticano II al nuovo Codice di diritto canonico, a cura di J. Beyer, G. Feliciani, H. Müller, Roma 1990, pp. 37-50.

Gelpi D.L., Committed Worship: The sacraments of ongoing conversion, Collegeville 1993.

Girardi L., Commento, in: Commentario ai documenti del Vaticano II. Sacrosanctum concilium. Inter mirifica, a cura di S. Noceti, R. Repole, Bologna 2014, pp. 145-172.

Giraudo C, Il Presbitero nella preghiera di ordinazione, in: Il Presbitero nella Chiesa dopo il Vaticano II, a cura di P. Sorci, Trapani 2005, pp. 50-71.

Gonneaud D., La sacramentalié du ministère diaconal, "Revue Théologique de Louvain" 36 (2005), pp. 3-20.

Gonneaud D., Pour le quarantiènne anniversaire du rétablissement de l'ordo diaconal: réflexions autour d'une maxime doctrinale, "Nouvelle Revue Théologique" 126 (2004), pp. 556-563.

Gouyon P., Les relations entre le diocèse et la conférence episcopale, "Lannée canonique" 22 (1978), pp. 1-23.

Gy P.M., La fonction des laics dans la liturgie, "La Maison-Dieu" 40 (1985), pp. 43-54.

Hammann G., Storia del diaconato, Magnano-Biella 2004.

Henry A.M., Mission d'hier, mission de demain, in: Lactivité missionnaire de l'Église. Décret "Ad gentes", a cura di J. Schütter, Paris 1967, pp. 411-440.

Hofinger P., Pastorale liturgica nella cristianità missionaria, Bruxelles 1957.

Hornef G., Winninger P., Cronaca della restaurazione del diaconato (1945-1965), in: Il diaconato nella Chiesa e nel mondo di oggi, Padova 1968, pp. 320-346.

Hornef J., Il diaconato a vita, "Concilium" 4 (1968), pp. 142-154.

Hornef J., The genesis and growth of the proposal, in: Fundations for the renewal of the diaconate, a cura di National Conference of Catholic Bishops - Bishops' Committee on the Permanent Diaconate, Washington DC 1993, pp. 4-23.

Iannone F., Per una rinnovata lettura ecclesiale dei segni dei tempi, "Credere oggi" 37 (2017), pp. 85-97.

Ignatius Antiochenus, Litteras ad Trallenses II, 1-3, ed. J. P. Migne, Patrologiae cursus completus, pp. 781-782. 
Insero W., La chiesa è "missionaria per sua natura" (AG 2); origine e contenuto dellaffermazione conciliare e la sua recezione nel dopo Concilio, Roma 2007.

Ioannes PP. XXIII., Sollemnis allocutio, 25.01.1959, AAS 51 (1959), pp. 65-69.

Ippolito Romanus, Traditio apostolica, in: Hippolyte de Rome. La Trdition Apostolique, ed. B. Botte, SCh, vol. 11 bis, Paris 1968.

Irti G., La pericoresi trinitaria: modello e fondamento della comunità evangelizzatrice nell'edificazione delle chiese locali, Roma 2004.

Karotemprel S., Chiesa e missione oggi, in: Il Concilio Vaticano II: recezione ed attualità alla luce del Giubileo, a cura di R. Fisichella, Cinisello Balsamo (MI) 2000, pp. 294-317.

Kramer H, Morche M, Caritas und Diakonatsbewegung in der ersten Phase (1905-1992), "Diaconia Christi” 29 (1994) 3-4, pp. 23-34.

Leclair D.M., The Deacon's participation in the Tria Munera in the Latin and Ukranian Catholic Churches: A historical-canonical Analysis, Ottava 2008.

Maggioni B., "Impara a conoscere il volto di Dio nelle parole di Dio". Commento alla "Dei Verbum», Padova 2001.

Malcherek R., Gemeinschaft von Gott und den Menschen. Überlegungen zur Liturgie als gottmenschlicher Dialog nach der Liturgiekonstitution des II. Vatikanischen Konzil, "Ecclesia orans" 18 (2001), pp. 237-268.

Mann von G., Der Caritasdiakonat und seine Erneurung, "Caritas" 7-8 (1934), pp. 5-12.

Manzanares J., De conferentiis episcopalibus post decem annos a Concilio Vaticano II, "Periodica" 64 (1975), pp. 586-601.

Marczewski M., Diakonat, in: Encyklopedia Katolicka, vol. III, a cura di R. Łukaszyk, L. Bieńkowski, F. Gryglewicz, Lublin 1979, col. 1245.

Marczewski M., Odnowa diakonatu stałego w Kościele łacińskim, "Novum” 4-5 (1979), p. $146-155$.

Martina G., Storia della Chiesa, vol. III-IV, Brescia 1995.

Martini C.M., La Parola di Dio alle origini, Roma 1980.

Martini C.M., La comunione presbiterale, Milano 2015.

Mazzolini S., Vocazione universale alla santità nella Chiesa, in: Commentario ai documenti del Vaticano II, a cura di S. Noceti, R. Repole, Roma 2006, pp. 345-378.

Miñambres J., Diritto canonico e servizio della carità, Milano 2008.

Monast J.E., On les croyait chrétiens, Paris 1969.

Mondin B., La Chiesa Sacramento d'amore: trattato di ecclesiologia, Bologna 1993.

Morche M., Zur Erneuerung des Ständigen Diakonats. Ein Beitrag zur Geschichte unter besonderer Berücksichtigung der Arbeit des Internationalen Diakonatszentrums in seiner Verbindung zum Deutschen Caritasverband, Freiburg 1996.

Moulinet D., La restauration conciliaire (1959-1964), in: Le diaconat permanent. Relectures et perspectives, ed. D. Moulinet, B. Dumons, Paris 2007, pp. 52-67.

Nocent A., Il tempo pasquale, in: Ĺanno liturgico. Storia, teologia e celebrazione, a cura di M. Augé, A. J. Chupungco, A. Nocent, M. Roonney, I. Scicolone, A. M. Triacca, Genova-Milano 1988, pp. 127-150. 
Noceti S., La costituzione gerarchica della Chiesa e in particolare l'episcopato, in: Commentario ai documenti del Vaticano II, a cura di S. Nocetti, R. Repole, Roma 2006, pp. 297-339.

Palazzini G., Il Concilio Ecumenico Vaticano II: tra cronaca e storia, Roma 1966.

Pesch O.H., Das zweite Vatikanische Konzil, Würzburg 1993.

Petrolino E., Diaconato. Servizio-missione dal Concilio Vaticano II a Giovanni Paolo II, Città del Vaticano 2006.

Petrolino E., Il Concilio Vaticano II e il diaconato. La Chiesa mistero di comunione e sevizio, Città del Vaticano 2013.

Philips G., La Chiesa e il suo mistero. Storia, testo e commento della Lumen Gentium, Milano 1975.

Pies O., Block 26: Erfahrungen aus dem Priesterleben in Dachau, "Stimmen der Zeit" 141 (1947-1948), pp. 10-28.

Pius PP. XII., Constitutio Apostolica de sacris Ordinibus Diaconatus, Presbyteratus et Episcopatus: Sacramentum Ordinis, 30.11.1947, AAS 40 (1948), pp. 5-7.

Pius PP. XII., Discours aux participants au IIe Congrés mondial dell'apostolat des laics, Samedi 5 octobre 1957, AAS 49 (1957), p. 925.

Plater O., Many Servants: An Introduction to Deacons, London 2004.

Policarpo, Secundus litterae ad Philippenses, in: Die Apostolischen Väter. Griechisch-deutsche parallelausgsche, vol. I, ed. F. X. Funk, K. Bihlmeyer, M. Whittaker, Tübingen 1992.

Rahner K., Lenseignement de Vatican II sur le diaconat et sa restauration, in: Le diacre dans l'Église et le monde d'aujourd'hui, a cura di P. Winninger, Y. Congar, Paris 1966, pp. 200-230.

Ramboldi G., Sacerdozio di Cristo e sacerdozio ministeriale nella Chiesa. Alcuni problemi di teologia sacerdotale, in: Sacerdozio e celibato. Studi storici e teologici, a cura di J. Coppens, Milano 1975, pp. 412-427.

Sacrosanctum Concilium Oecumenicum Vaticanum II, Constitutio de sacra Liturgia Sacrosanctum Concilium, 4.12.1963, AAS 56 (1964), pp. 97-138.

Sacrosanctum Concilium Oecumenicum Vaticanum II, Constitutio dogmatica de Ecclesia Lumen gentium, 21.11.1964, AAS 57 (1965), pp. 5-71.

Sacrosanctum Concilium Oecumenicum Vaticanum II, Decretum de Ecclesiis orientalibus catholicis Orientalium Ecclesiarum, 21.11.1964, AAS 57 (1965), pp. 76-89.

Sacrosanctum Concilium Oecumenicum Vaticanum II, Decretum de pastorali Episcoporum munere in Ecclesia Christus Dominus, 28.10.1965, AAS 58 (1966), pp. 673-701.

Sacrosanctum Concilium Oecumenicum Vaticanum II, Constitutio dogmatica de Divina Revelatione Dei Verbum, 18.11.1965, AAS 58 (1966), pp. 817-835.

Sacrosanctum Concilium Oecumenicum Vaticanum II, Decretum de activitate missionali Ecclesiae Ad gentes divinitus, 7.12.1965, AAS 58 (1966), pp. 948-990.

Sander S., Das Amt des Diakons. Eine Handreichung, Freiburg im Breisgau 2008.

Schamoni W., Familienväter als geweihte Diakone, Paderborn 1953. 
Selejdak R., Diakonat stały w świetle dokumentów Soboru Watykańskiego II, posoborowego Urzędu Nauczycielskiego Kościoła i narodowych «Rationes institutionis diaconorum permanentium», Warszawa 2010.

Siviglia I., Il discernimento ecclesiale, "Ho Théologos" 13 (1995), pp. 32-41.

Statuta Ecclesiae Antiqua, in: Concilia Galliae a. 314-505, ed. C. Munier, Turnholt 1963.

Stickler A.M., La continenza dei diaconi specialmente nel primo millennio della Chiesa, “Salesianum” 26 (1964), pp. 275-302.

Taft R., Cosa fa la liturgia? Verso una soteriologia della celebrazione liturgica. Alcuni testi, "Communio" 21 (1993), pp. 8-25.

Teuffenbach von A., La commissione teologica preparatoria del Concilio Vaticano II, "Annuario de Historia de la Iglesia” 21 (2012), pp. 221-233. Vitali D., Per una teologia del diaconato: la lezione conciliare, "Rassegna di Teologia” 55 (2014), pp. 111-132. Vorgrimler H., Commento allarticolo 29 di Lumen gentium, in: La gerarchia nella Chiesa. Commento al Capitolo III di Lumen gentium, a cura di K. Rahner, Brescia 2008, pp. 60-85.

Weber P., Vatican II et le diaconat permanent, in: Diaconat XXI siècle. Actes du colloque de Louvain-la Neuve (13-15 settembre 1991), a cura di A. Haquin, P.Weber, Bruxelles-Ottawa-Paris-Genève 1997, pp. 87-120.

Zambon G., Laicato e tipologie ecclesiali: ricerca storica sulla teologia del laicato in Italia alla luce del Concilio Vaticano II (1950-1980), Roma 1996.

Zardoni S., I diaconi nella Chiesa. Ricerca storica e teologica sul diaconato, Bologna 1990.

Zizioulas J., L'Eucaristie, l'evêque et l'Eglise durant les premiers siècles, Paris 1994. 